Wayne State University

DigitalCommons@WayneState

Sociology Faculty Research Publications

Sociology

$1-1-2008$

\title{
Income Diversity Within Neighborhoods and Very Low-Income Families
}

\author{
George C. Galster \\ Wayne State University, GEORGE_GALSTER@WAYNE.EDU \\ Jason C. Booza \\ Wayne State University, jbooza@med.wayne.edu \\ Jackie M. Cutsinger \\ Wayne State University, jackiecutsinger@wayne.edu
}

\section{Recommended Citation}

Galster, G. C., Booza, J. C., \& Cutsinger, J. M. (2008). Income diversity within neighborhoods and very low-income familites. Cityscape, 10(2), 257-300.

Available at: http://digitalcommons.wayne.edu/socfrp/1

This Article is brought to you for free and open access by the Sociology at DigitalCommons@WayneState. It has been accepted for inclusion in Sociology Faculty Research Publications by an authorized administrator of DigitalCommons@WayneState. 


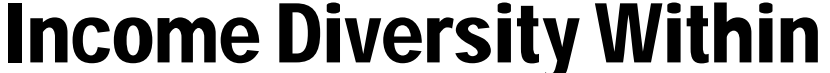

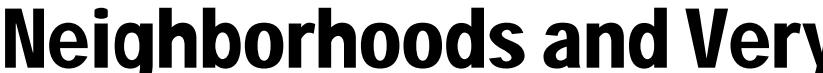

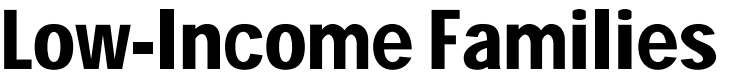

\author{
George C. Galster \\ Jason C. Booza \\ Jackie M. Cutsinger \\ Wayne State University
}

This research was supported by a grant from the U.S. Department of Housing and Urban Development, Office of Policy Development and Research. The opinions expressed in this article are those of the authors and do not necessarily reflect those of the Department.

\section{Abstract}

The past decades have witnessed increasing concern over the family ills engendered by neighborhoods inhabited overwhelmingly by families with limited resources. This study focuses on a different sort of residential context-neighborhoods with substantial income mixing - and the extent to which very low-income (VLI) families - those earning less than 50 percent of the area median income (AMI) -live in them. The study's primary units of analysis are the 100 largest metropolitan areas in the United States, according to the 2000 Census, and the secondary units of analysis are census tracts. The study specifies six mutually exclusive income groups based on the ratios relative to AMI, as defined by the U.S. Department of Housing and Urban Development. It also specifies four groups of neighborhoods according to their diversity of the six income groups, as measured by an entropy index. The descriptive results show that in 2000 (1) most neighborhoods had high diversity, although a decline is apparent in the overall income diversity of neighborhoods and in the share comprising high-diversity neighborhoods; (2) no neighborhoods with median incomes of less than 50 percent of AMI had high diversity; (3) 19 percent of all high-diversity neighborhoods (on average) consist of VLI families and 65 percent of all VLI families live in high-diversity neighborhoods, although both percentages have declined since 1970; (4) 5 percent of VLI families live in neighborhoods with median incomes of less than 50 percent of AMI, twice the percentage of 1970 but lower than in 1990; and (5) exposure of VLI families to other VLI families and moderate-income groups has steadily fallen since 1970 and concomitantly increased for families that have very high incomes (VHIs); indeed, the exposure to VHI families is approximately the same as exposure to other VLI families. This article addresses the mixed implications of these trends for the potential socioeconomic mobility of VLI families. 


\section{1)}

During the past two decades, increasing concern has arisen in many arenas concerning the family ills and impediments to upward socioeconomic mobility engendered by neighborhoods housing only those of limited economic means (for reviews, see Ellen and Turner, 2003; Leventhal and Brooks-Gunn, 2000; Sampson, Morenoff, and Gannon-Rowley, 2002). Regardless of whether such neighborhoods of concentrated deprivation have been generated by market forces or misguided housing policy, a consensus has arisen that they represent a serious problem. As a result, beginning in the 1990s, federal housing policy increasingly emphasized the deconcentration of very low-income (VLI) families, employing both demand- and supply-side housing assistance strategies. On the demand side, efforts were made to aid recipients of Section 8 (now Housing Choice) vouchers in finding apartments in more income-diverse communities. On the supply side, both HOPE VI public housing revitalization programs and public housing desegregation consent decrees worked toward increasing options for public housing residents to either move to low-poverty neighborhoods elsewhere or reside in new, mixed-income communities developed on site. Given these public concerns and federal policy initiatives, it is appropriate to inventory the extent to which VLI families reside today in more diverse alternatives, instead of in neighborhoods of concentrated deprivation.

There has been little systematic description and analysis of income-diverse neighborhoods across our major metropolitan areas and the degree to which VLI families live in them. We do not know enough about how the incidence of income-diverse neighborhoods in U.S. metropolitan areas has changed over time, how prevalent such neighborhoods are today, and the degree to which VLI families are exposed to them. We do not know enough about which other income groups live with VLI families in diverse neighborhoods, despite the importance of such diversity for intraneighborhood social interactions that can potentially benefit VLI families. The current research addresses these important gaps in our knowledge.

In particular, our study addresses the following questions:

- How much income diversity within neighborhoods is present in the 100 largest U.S. metropolitan areas in 2000 and how has the diversity changed since 1970?

- What share of VLI families lives in income-diverse neighborhoods during the 1970-to-2000 period?

- What higher income groups are typically present in neighborhoods occupied by VLI families?

To answer these questions we analyze census tract data for the 100 largest U.S. metropolitan areas in 2000 for the decadal censuses 1970 to 2000, which are contained in the Neighborhood Change Database (NCDB). But first, to situate our research within the existing framework of knowledge about income mixing in neighborhoods, we review the relevant literature.

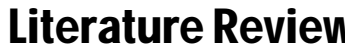

A great deal of research has been conducted concerning urban economic inequality among groups and residential racial/ethnic segregation. As Jargowsky (1996a) points out, however, another 
important aspect of socioeconomic differentiation-the distribution of economic groups across and within neighborhoods-has received less attention. Studies of economic segregation (that is, summary measures of the spatial distribution of different economic groups across neighborhoods comprising an entire metropolitan area) include Abramson, Tobin, and VanderGoot (1995); Jargowsky (1996a, 1997); Massey and Eggers (1993); Massey and Fischer (2003); Mayer (2001); Swanstrom et al. (2004); and Watson (2007). These studies are of less relevance to this article compared to those that analyze within-neighborhood diversity directly. We will briefly review these latter studies, explaining how they measure key concepts and what their main conclusions have been. We close the section by showing our study's contribution to this literature.

\section{Studies of Income Diversity Within Neighborhoods}

The modestly scaled empirical literature that considers the mix of economic groups within neighborhoods includes Hardman and Ioannides (2004a, 2004b); Immergluck and Smith (2002); Ioannides (2004); Ioannides and Seslen (2002); Jargowsky (1996b, 1997); Krupka (2006); Thomas, Schweitzer, and Darnton (2004); Talen (2006); and Turner and Fenderson (2006). These studies focus on many of the same questions as our study does. How much income diversity characterizes American neighborhoods? How frequently do high-diversity neighborhoods occur? What are their characteristics? How stable are they? What metropolitanwide forces seem to affect neighborhood-level diversity? The common finding is that a significant amount of income diversity typically is present in U.S. neighborhoods (Hardman and Ioannides, 2004a, 2004b; Ioannides, 2004; Ioannides and Seslen, 2002; Krupka, 2006; Talen, 2006; Turner and Fenderson, 2006), even those neighborhoods with poverty rates of more than 40 percent (Jargowsky, 1996b). Much less is known about trends in income-diverse neighborhoods, however, and the extent to which VLI families constitute a substantial part of the mix.

Immergluck and Smith (2002) and Thomas, Schweitzer, and Darnton (2004) classify neighborhoods in Chicago and Grand Rapids, respectively, according to their internal income distributions; Turner and Fenderson (2006) do the same for a national sample of neighborhoods. These studies assign neighborhoods to groups arbitrarily according to their internal income distributions. Immergluck and Smith (2002) categorize neighborhoods in the Chicago area as "highly restrictive," "moderately restrictive," "moderately diverse," "highly diverse," or "low-moderate income" based on the mix of lower and upper income residents in the neighborhood. They identify 72 moderately diverse neighborhoods and 21 highly diverse neighborhoods that were stable from 1993 to 2000. ${ }^{1}$ Thomas, Schweitzer, and Darnton (2004) define mixed-income neighborhoods as those reflecting the mix of incomes that exists in the greater urban area. They identify a total of 11 block groups that are both diverse and stable from 1990 to 2000 in their income mix. These 11 neighborhoods tended to have less vacant housing, less rental housing, lower median income than the metropolitan area, lower proportions of families in poverty, and fewer people of color. Turner and Fenderson (2006) specify income groups according to national quintiles of the 2000 Public Use Microdata Sample, then categorize census tracts into 12 groups according to their share of lowest quintile households and mixes of higher income groups. They find a substantial incidence of income-

\footnotetext{
${ }^{1}$ The authors define stability as fluctuations that are less than plus or minus 5 percentage points during the study period.
} 
diverse neighborhoods, with the greatest income mixing in neighborhoods with 10 to 20 percent of lowest quintile households. Conversely, middle- and high-income households are most likely to predominate in tracts with the smallest share of the lowest income group.

Hardman and Ioannides (2004a, 2004b) assess income mixing at the microneighborhood level by using clusters of 11 adjacent homes delineated by the American Housing Survey (AHS). In both studies, the authors measure income as a proportion of the adjusted median family income, as defined by the U.S. Department of Housing and Urban Development (HUD). They find that households that are most likely to live in neighborhoods with medians close to theirs are the richest, followed by the poorest households. They find evidence for some "perfect sorting" (that is, neighborhoods made up of concentrations of households in which all have very similar incomes) in many neighborhoods at both extremes of the income distribution, so it is more likely that neighborhoods with median incomes near the center of the income distribution will be diverse.

Ioannides and Seslen (2002) investigate the distribution of both income and wealth in neighborhoods and contrast these with national income and wealth distributions, using data from the AHS and the Panel Study of Income Dynamics. ${ }^{2}$ They employ the Bourguignon decomposable inequality index in their analyses. Housing value showed the smallest amount of diversity within neighborhoods, followed by income, then total net wealth.

Jargowsky (1996b, 1997) comprehensively studies metropolitan neighborhoods where the percentage of population below the federal poverty line is greater than 40 percent. He finds that these neighborhoods are occupied predominantly by African Americans, often by Hispanics, and rarely by Whites. Concentrated poverty neighborhoods increased in prevalence from 1970 to 1990 (measured by the number of 40-percent poor census tracts and the populations living in them). During the 1990s, however, this trend seems to have abated (Jargowsky, 2003). Despite their concentrations of poverty, however, these neighborhoods contain considerable amounts of diversity on a variety of socioeconomic indicators (Jargowsky, 1996b).

Ioannides (2004), Krupka (2006), and Talen (2006) use multivariate techniques to probe the correlates of neighborhood income diversity. Ioannides uses a national AHS sample of microneighborhoods and measures income diversity by the variance of the natural log transformation of household incomes of those residing there. Talen uses census tracts in Chicago and measures income diversity by an entropy index based on Census-reported income groups. Krupka (2006) measures income diversity of block groups using the variance of Census-defined income group midpoints. Despite the variation in diversity measures and geographic scales of neighborhood analyzed, these studies consistently find a greater likelihood of income mixing in neighborhoods with more owner occupants, families with children, and non-White households; higher densities; lower vacancy rates; older housing stock; and greater diversity of housing by tenure and values. The evidence on housing values is contradictory, however.

\footnotetext{
${ }^{2}$ Ioannides and Seslen (2002) measure income synonymously as the Census Bureau defines family income.
} 


\section{The Contributions of This Study}

This study contributes to the literature on neighborhood income diversity in two primary ways. First, for neighborhoods in the 100 largest U.S. metropolitan areas in 2000 we provide a series of comprehensive portraits from 1970 to 2000 of the distribution of six family-income groups, which are defined consistently across the nation and across time through the use of HUD's scheme relating them to metropolitan area median incomes (AMIs). In these portraits we present distributions of neighborhoods according to their degree of income diversity (measured by entropy). We also provide representative illustrations of neighborhoods within various groups of income diversity in five large metropolitan areas. Second, we focus on the residential experience of VLI families, tracing in detail the groups of neighborhoods that they occupy in terms of the income of their neighbors. This view provides much more nuance than the poor/nonpoor dichotomous analyses that have often been conducted.

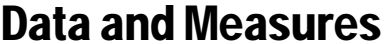

This data and measures section discusses the data, variables, and methods we used in the study. We start with the parameters of the study, time frame, and units of analysis. We proceed by describing our data sources and index measures.

\section{Spatial and Temporal Parameters}

The timeframe considered in this study is 1970 to 2000, with observations made at the following points in time: 1970, 1980, 1990, and 2000. We selected the 1970-to-2000 period for two reasons. First, before 1970 the requisite census tract data are either unavailable or cumbersome to employ. ${ }^{3}$ Second, selecting the 1970-to-2000 period permits comparison of our findings with those of previous research (Abramson, Tobin, and VanderGoot, 1995; Farley, 1977; Massey and Eggers, 1993, 1990).

Spatially, we employ two types of units of analysis in this study: one primary and one secondary. Our primary units of analysis are the 100 largest U.S. metropolitan areas-metropolitan statistical areas (MSAs) and primary metropolitan statistical areas (PMSAs) —in the United States, according to the 2000 Census (see appendix A). Advantages to using the 100 largest U.S. metropolitan areas as the primary unit of analysis include (1) a reliable, adequately sized data set, (2) a representative regional sampling of the United States, and (3) a sample accounting for 61.4 percent ( $\mathrm{N}=172,896,354)$ of the total U.S. population in 2000 (http://factfinder.census.gov).

Following the reasoning of Abramson, Tobin, and VanderGoot (1995), we chose the metropolitan area as our primary unit of analysis because, by definition, its boundaries capture the widest range of income diversity in our urban regions. The alternative used in some other studies has been to focus on central cities. With the decline of central city population as a share of the region, especially

\footnotetext{
${ }^{3}$ Several data sets exist that contain tract-level data for the period of 1940 to 1970, including the Elizabeth and Donald Bogue data series housed at the University of Michigan's Inter-University Consortium for Political and Social Research (www.icpsr.org). Usability of the data, however, is cumbersome and, more importantly, not all of the metropolitan areas included in this study are covered uniformly over time.
} 
in the Midwest and Northeast, however, we believe that central cities are not the best unit of analysis because they provide only a limited glimpse of the metropolitan neighborhood income spectrum.

As with most units of geography used in the U.S. Census, however, metropolitan area boundaries may change over time. ${ }^{4}$ Providing a constant definition to metropolitan areas across our 30-year timeframe would be artificial and inappropriate. ${ }^{5}$ We have chosen instead to use for metropolitan areas whichever boundaries were appropriate for the year in which particular data were measured. This means that we are allowing the boundaries of the metropolitan areas to change for each census period, thus permitting us to capture the full range of income diversity for the population then residing in each area. We agree with Abramson, Tobin, and VanderGoot (1995: 48-49) that "the changing boundaries of metropolitan areas generally reflect real changes in the way the areas are organized and should be incorporated into the analysis" (see also Jargowsky, 1994).

In keeping with most other quantitative studies that involved analysis of neighborhood income dynamics, we chose to use census tracts as our secondary unit of analysis (also see Abramson, Tobin, and VanderGoot, 1995; Galster and Mincy, 1993; Galster, Quercia, Cortes, et al., 2003; Jargowsky, 1997, 1994; Kasarda, 1993; Massey and Denton, 1988; Massey and Eggers, 1993, 1990). According to Iceland, Weinberg, and Steinmetz (2002: 8), "census tracts, which typically have between 2,500 and 8,000 people, are defined with local input, are intended to represent neighborhoods, and typically do not change much from census to census, except to subdivide." Although not without controversy ${ }^{6}$ census tracts remain the overwhelming choice of analysis, whether measuring income, race, or any other type of neighborhood-based measure of inequality.

Although the census tract is a key component to our research, we thought that the inclusion of all tracts would be inappropriate for this study. After considering our review of previous research (Ellen, 1998; Lee and Wood, 1990), we decided that census tracts had to meet the following criteria to be included in this study:

- A total population of 500 or greater.

- A group-quarters population that is not more than 50 percent of the total population.

- A reported family-income distribution. ${ }^{7}$

\footnotetext{
${ }^{4}$ Metropolitan areas have changed numerous times between 1970 and 2000—new ones have been created, some have expanded due to growth in outlying counties, and others have been subdivided based on changes in commuting trends. The U.S. Office of Management and Budget redefines metropolitan areas after each census as new data on population and commuting become available.

${ }^{5}$ One option would have been to include in subsequent years only those census tracts that constituted our 1970 sample of metropolitan areas, but this approach would have excluded areas of post-1970 suburban growth. Another option would have been to work backward from all tracts constituting metropolitan areas in 2000, but this approach would have produced many missing observations, because not all areas of the country were tracted in 1970 and 1980 (Tatian, 2002).

${ }^{6}$ According to Massey and Denton (1988), census tracts possess two flaws. First, by definition, they are intended to be homogenous in terms of race/ethnicity, income, occupation, and housing. Second, disparities exist in the geographic size of tracts between central cities and suburbs because population rather than geography determines tract size. In areas where the population is less dense (for example, outlying suburbs) census tracts tend to be larger when compared to more dense tracts in central cities. Yet, according to Massey and Denton (1988), "switching down to blocks or up to tract groups will not eliminate any of the problems."

${ }^{7}$ Because of respondent confidentiality, certain demographic measures such as income are suppressed under certain circumstances. Thus, we were presented with several situations in which we were provided with total population and racial characteristics but no income statistics.
} 
Selecting tracts with a population greater than 500 provides us with a threshold that helps ensure a robust sample size for each tract. In addition, tracts with large group-quarters populations (prisons, college dorms, nursing homes) are irrelevant to this study and are excluded to prevent them from skewing our results. Finally, and most importantly, tracts without income data were eliminated from the sample.

We recognize that, despite its many analytical advantages, the census tract may not be the ideal unit of analysis for operationalizing "neighborhood." We note that urban residents conceive of several spatial scales of neighborhood, the smallest consisting of their own blockface (Suttles, 1972). Moreover, it is conceivable that census tracts are of a scale that internal segregation of different income groups may be possible. Thus, we urge caution when interpreting findings in this article to recognize that the calculated exposure of different groups to each other in the same census tract does not necessarily mean that these groups live on the same blocks or that they interact meaningfully or in a sustained way.

\section{Data Sources}

The primary data source used in the study is the Neighborhood Change Database (NCDB), which was created by GeoLytics, Inc., in conjunction with the Urban Institute. We used the NCDB census long form database, which contains sample data from the 1970, 1980, 1990, and 2000 Censuses. Using the NCDB provides the advantage of having an extensive and high-quality set of census data in an easy-to-access format. With just this one database, we were able to conduct with extraordinary efficiency census tract analysis across a 30-year timeframe. ${ }^{8}$

In addition to accessing information from the $\mathrm{NCDB}$, we needed to obtain metropolitan-level characteristics for measures of income. Because the NCDB contains only tract-level data, median family-income statistics measured at the metropolitan level were obtained from other sources. We used Census-printed reports for 1970 and 1980 (U.S. Bureau of the Census, 1973, 1981). For 1990 and 2000 data we used the Census Bureau's FactFinder website (http://factfinder.census.gov). To create additional metropolitan-level variables used in our analyses, we aggregated census tract data, resulting in metropolitan area totals.

\section{Socioeconomic Variables}

The first set of variables that form the foundation of our study is the family-income distribution. ${ }^{9}$ The NCDB provides a grouped frequency distribution of family income for each decade by census

\footnotetext{
${ }^{8}$ An alternative, cumbersome method would have been to assemble four national files by assembling state files for each of the four censuses. The files would then have had to be "cleaned" to sort out any unwanted variables and census tracts.

${ }^{9}$ The U.S. Census Bureau defines a family as two or more people who are related by birth, marriage, or adoption and living in the same household. Households represent all persons living together in a housing unit, and families are a type of household. Studies of income segregation use either households or families as the base of their income measure. Although the pattern of income distribution is likely not to differ, there are income differences between the two. Because households include families, unrelated persons, and persons living alone, it is a more inclusive measure leading to lower median income results than with families. Families do not include unrelated individuals or one-person households, thus resulting in income ranges and medians that trend higher. In this study, we have chosen to use families as the basis for our income calculations because NCDB does not provide household income distribution for the years before 2000 and because HUD uses the family as its unit of analysis for its programmatic income guidelines.
} 
tract. From these distributions, we calculated family-income groupings based on HUD income guidelines (see HUD, 1996: appendix B). We specified the following six mutually exclusive income groups, based on the area median income $e^{10}$ of families for the particular metropolitan area:

1. Very low-income (VLI) group: families earning 50 percent or less of AMI.

2. Low-income (LI) group: families earning 51 to 80 percent of AMI.

3. Moderate-income (MI) group: families earning 81 to 100 percent of AMI.

4. High-moderate-income (HMI) group: families earning 101 to 120 percent of AMI.

5. High-income (HI) group: families earning 121 to 150 percent of AMI.

6. Very high-income (VHI) group: families earning more than 150 percent of AMI.

Although not based on the same criteria that the Census Bureau uses when considering poverty, our VLI group generally measures the similar end of the income distribution, albeit more expansively, in most of our largest metropolitan areas. Our specification offers several advantages over the conventional use of the federally defined poverty line to create a simple dichotomy of poor and nonpoor, however. First, we are able to control implicitly for regional and metropolitan differences in income levels and cost of living by providing a standard that is based on each metropolitan area's median income. Second, because we are standardizing income distribution groups across metropolitan areas by relating each to its own AMI, we are able to make straightforward comparisons among metropolitan areas, both cross-sectionally and over time.

Although the grouped family-income distribution found in the NCDB provides us with the necessary data to create our six income groups, we were confronted by the fact that their numerical boundaries defined by HUD guidelines did not match the grouped NCDB income distribution data. Based on U.S. Census procedures (U.S. Bureau of the Census, 2002), we interpolated the data in the NCDB groups to obtain a reasonably accurate estimate of family counts within our six income groups. For the income range of $\$ 2,500$ or less, we used linear interpolation and, for larger income ranges, we used Pareto interpolation (see appendix B for formulae).

\section{Index Measures}

We use two indices in our study; both use the aforementioned definitions of income groups, thereby enabling us to get beyond the poor/nonpoor dichotomy found in much of the previous research on metropolitan income inequality. The first is the $\mathrm{P}^{*}$ index $\left(\mathrm{xP}^{*} \mathrm{y}\right)$, which measures the exposure of one group (x) to another (y) (Massey and Denton, 1988):11

$$
{ }_{x} P_{y}^{*}=\sum_{i=1}^{n} \frac{x_{i}}{X} \frac{y_{i}}{t_{i}}
$$

\footnotetext{
${ }^{10}$ The AMI we use is not adjusted for differences in family size.

${ }^{11}$ Note: when $X$ and $Y$ represent the same group, the index is referred to as an isolation index.
} 
where:

$x_{i}=$ Number of group $X$ members

$y_{i}=$ Number of group $Y$ members

$t_{i}=$ Total population of unit $i$

$X=$ Total population of $X$ members of the whole metropolitan area

The index varies between 0 and 1.0 and is interpreted in this study as the probability that a member of a very low-income group $(x)$ will share the same neighborhood (census tract) with a member of another, higher income group (y). It also may be interpreted as the average percentage of group $y$ residing in the neighborhood of group $x$ families. In most studies of income inequality, the exposure index is computed for the poor and measures the degree to which they are exposed to the nonpoor income group. Instead, we compute exposure for VLI families to each individual higher income group in our six-group typology, thus providing a much richer portrait of the composition of the typical VLI family's neighborhood.

The other measure we employ is the entropy index $(\mathrm{H})$ :

$\mathrm{M}$

$\mathrm{H}_{\mathrm{i}}=\Sigma \mathrm{Q}_{\mathrm{im}} / \ln (\mathrm{M})$

$\mathrm{m}=1$

where:

$\mathrm{Q}_{\mathrm{im}}=-\pi_{\mathrm{im}} \ln \left(\pi_{\mathrm{im}}\right)$ if $\pi_{\mathrm{im}}>0$

$=0$ otherwise

$\pi_{i m}=$ the proportion of the population of tract i consisting of individuals from group

$\mathrm{m}(m=1,2, \ldots, M)$

$M=$ Number of groups (six in our study)

$\mathrm{H}$ provides a measure of how evenly families are distributed across the various income groups within a neighborhood. It assumes its maximum value of 1.0 when each of the aforementioned six income groups is equally represented in the neighborhood. It assumes its minimum value of zero when only one of the groups is represented in the neighborhood. Many scholars have confirmed the usefulness of the entropy index and its numerous desirable technical qualities, such as handling multiple groups readily, easy calculation, and decomposability (Allison, 1978; Fischer, 2003; Iceland, 2004; James and Taeuber, 1985; Reardon and Firebaugh, 2002; Reardon and Yun, 2001; White, 1986). Entropy has been chosen as the preferred measure in a wide range of studies on income inequality and economic segregation (Firebaugh, 1999; Fischer, 2003; Fischer et al., 2004; Fong and Shibuya, 2000; Harsman and Quigley, 1995; Jones and Weinberg, 2000; Talen, 2006; Telles, 1995; White, 1986), and we follow in this tradition. ${ }^{12}$

\footnotetext{
${ }^{12}$ Several other measures of income diversity within neighborhoods have been employed, of course; cf. Hardman and Ioannides (2004a, 2004b); Immergluck and Smith (2002); Ioannides (2004); Krupka (2006); Thomas, Schweitzer, and Darnton (2004); Turner and Fenderson (2006).
} 


\section{Neighborhood Income Diversity Typology}

After computing some measure of the diversity of income groups within a neighborhood, any study is confronted next with the challenge of specifying ranges of values for this measure that serve to categorize neighborhoods into various diversity groups. This process is inherently arbitrary and fraught with potential tautology: how one chooses the group definitions can shape the conclusions one reaches. Our approach appeals fundamentally to an intuitively pleasing, commonlanguage notion of what constitutes diversity, then translates this into corresponding values of our entropy index for operationalization. Our approach thus does not beg the question of the incidence or distribution of neighborhoods according to our typology.

Specifically, our typology of income diversity at the neighborhood level has four groups (high diversity, moderate diversity, low diversity, and not diverse) defined intuitively and by entropy as follows:

\begin{tabular}{llc}
\hline \multicolumn{1}{c}{ Group Title } & Income Group Mix Defining Minimum Threshold & Entropy Range \\
High diversity & 1 group $=33.3 \%, 4$ groups $=16.7 \%, 1$ group $=0 \%$ & $.87 \leq \mathrm{H}$ \\
Moderate diversity & 1 group $=50 \%, 3$ groups $=16.7 \%, 2$ groups $=0 \%$ & $.69 \leq \mathrm{H}<.87$ \\
Low diversity & 1 group $=66.7 \%, 2$ groups $=16.7 \%, 3$ groups $=0 \%$ & $.48 \leq \mathrm{H}<.69$ \\
Not diverse & NA & $\mathrm{H}<.48$ \\
\hline
\end{tabular}

For a census tract to have high diversity, we think it reasonable to specify that it must meet the standard of four of the six income groups being represented to a substantial degree: each comprising at least 16.7 percent (one-sixth) and none exceeding 33.3 percent (one-third) of the population. This mixture translates into an entropy value of 0.87 . We therefore categorize as "high diversity" any neighborhood meeting or exceeding this degree of diversity as embodied in this threshold entropy score. Exhibit 1 shows what an archetypical neighborhood of 18 dwellings might look like under our specification of high diversity. Similarly, the threshold for achieving a moderate-diversity neighborhood is one group comprising 50 percent of the population, three other groups at 16.7 percent, and two groups not represented, which corresponds to an entropy score of 0.69 . Finally, the low-diversity neighborhood threshold is defined as one group at 66.7 percent, two groups at 16.7 percent each, and three groups not represented, which corresponds to an entropy score of 0.48 . Anything less than this limited mixture is defined as "not diverse" in our scheme.

\section{Neighborhood Median Income Typology}

We also find it revealing in some of our analyses to categorize neighborhoods by their median family incomes (not their diversity of incomes). We thus define six groups of neighborhoods according to whether their median family income falls within one of the aforementioned six HUD income ranges. Thus, a "VLI neighborhood" means a census tract whose median family income was less than 50 percent of the area median income. Across our 100 largest U.S. metropolitan areas in 2000, the (unweighted) mean percentages of neighborhoods falling into these six neighborhood median income groups were as follows: VLI: 7.3 percent; LI: 23.8 percent; MI: 24.1 percent; HMI: 19.4 percent; HI: 15.3 percent; and VHI: 10.0 percent. Comparable statistics for individual metropolitan areas are presented in appendix A. 


\section{Exhibit 1}

\section{Neighborhood Diversity Archetypes by Income-Group Composition}

High-Diversity Neighborhood

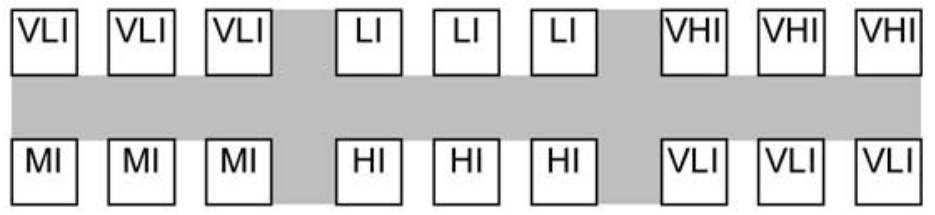

Moderate-Diversity Neighborhood

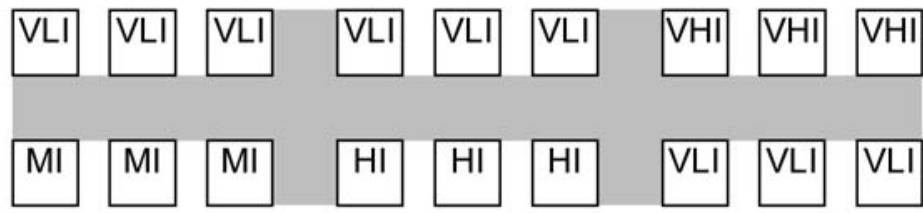

Low-Diversity Neighborhood

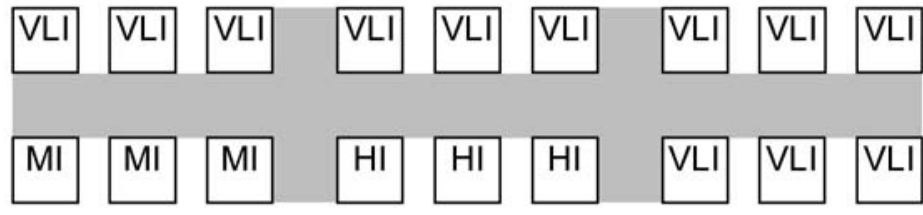

$\mathrm{HI}=$ high income. $\mathrm{LI}=$ low income. $\mathrm{MI}=$ moderate income. $\mathrm{VHI}=$ very high income. $\mathrm{VLI}=$ very low income.

\section{An Application of Our Neighborhood Income-Diversity Typology to Five Cities}

We believe that our scheme for delineating groups of neighborhoods according to their entropy score has scientific and intuitive appeal; however, it is also vital to "ground test" the scheme in well-known neighborhoods to ensure that it comports well with commonsensical understandings. We do so in this section by mapping our four groups of neighborhood income diversity in five different metropolitan areas: Los Angeles, New York, Chicago, the District of Columbia, and Detroit. All maps follow the same format, whereby darker shades signify greater income diversity.

The map in exhibit 2 shows census tracts in the central region of Los Angeles. Note the vast swath of low-diversity neighborhoods extending through the central part of the city from the municipal civic core to the Watts and South Central areas. These neighborhoods are composed of predominately VLI and LI African-American and Latino families. Similarly, low-diversity but VHI White neighborhoods are observed in Beverly Hills, the Hollywood Hills just north, and the oceanfront communities of Santa Monica and Palos Verdes. Separating these two groups of low-diversity communities is a broad ring of high-diversity, moderate-income neighborhoods.

The central boroughs of New York are shown on the map in exhibit 3. The homogenous, VHI enclave of the Manhattan Upper East Side stands out dramatically on the east edge of Central Park (shown as large white rectangle). A similar cluster of $\mathrm{HI}$ and VHI neighborhoods is evident around Greenwich Village. By contrast, Chelsea, Harlem, and the Lower East Side evince considerably 
more income diversity. Large swaths of high-diversity neighborhoods are obvious in the northern realms of Brooklyn and western realms of Queens (just east across the East River from Manhattan). Pockets of LI and VLI African-American neighborhoods evincing little diversity appear in the South Bronx (just east of Harlem).

Chicago and some of surrounding Cook County are shown on the map in exhibit 4. Substantial spatial irregularities exist in the older core neighborhoods of the city. Several homogenous (predominantly White) HI and VHI neighborhoods extend north and west from the "loop" central business district, epitomized by the "Gold Coast" running north through Lincoln Park adjacent to Lake Michigan. A contrasting band of homogenously VLI (predominantly African-American) neighborhoods extends south from the core, encompassing the now demolished) public housing projects (such as Robert Taylor homes) along State Street and continuing into Woodlawn and Englewood. The well-known, economically (and racially) diverse communities of Uptown and Hyde Park are clearly demarcated. Forming a wide crescent around this mixture of neighborhood groups in the core is a set of high-diversity, MI neighborhoods extending from Chicago into the inner-ring suburbs.

The District of Columbia is shown on the map in exhibit 5. Both Capitol Hill and Columbia Heights were under considerable gentrification pressure in 2000 and appropriately reflect moderate to high degrees of diversity. A wide swath of high-diversity (racially mixed) neighborhoods radiates northwest along the east side of Connecticut Avenue from Dupont Circle. Another (predominately African-American) set of high-diversity, MI neighborhoods extends from the northeast quadrant of the District into Prince George's County, Maryland. By contract, a swath of homogenous (predominately White) HI and VHI neighborhoods extends northwest from the Georgetown neighborhood in the District into the adjacent suburbs of Montgomery County, Maryland.

Finally, the core of the Detroit metropolitan area is shown on the map in exhibit 6 . The pockets of high-diversity neighborhoods bordering the central business district along the Detroit River reflect a spotty pattern of small-scale redevelopment amid older, poor-quality housing. Just north of the central business district in the Cass Corridor, a group of homogenously VLI and LI (predominately African-American) neighborhoods is being diversified by gentrification pressures on the south flank of Wayne State University. The crescent-shaped pattern of low-diversity neighborhoods centered around Highland Park consists of homogenously poor areas, most of which were designated as Empowerment Zone territories. As in the case of Chicago, this polyglot pattern at the core changes into a consistent ring of high-diversity, MI neighborhoods constituting a vast area of southern Macomb County (for example, Warren), southern Oakland County, and western Wayne County. At the other extreme, the suburb of Grosse Pointe clearly appears as a not-diverse enclave, consistent with its homogenously VHI (White) population. Similar groups of neighborhoods appear in the northwestern reaches of Oakland County (for example, Bloomfield Hills, Birmingham).

In sum, we believe that our groups for neighborhood income diversity make sense when applied to a wide range of contexts in five of our largest metropolitan areas. This cartographic exploration also reveals some rough similarities in the spatial patterns of neighborhood income diversity. The core areas of our largest metropolitan areas generally are characterized by a more jumbled pattern, with a wide range of neighborhood diversity groups represented in a relatively small territory. High-diversity, moderate-diversity, not-diverse/HI, and not-diverse/LI groups all are typically 


\section{Exhibit 2}

Los Angeles PMSA, 2000

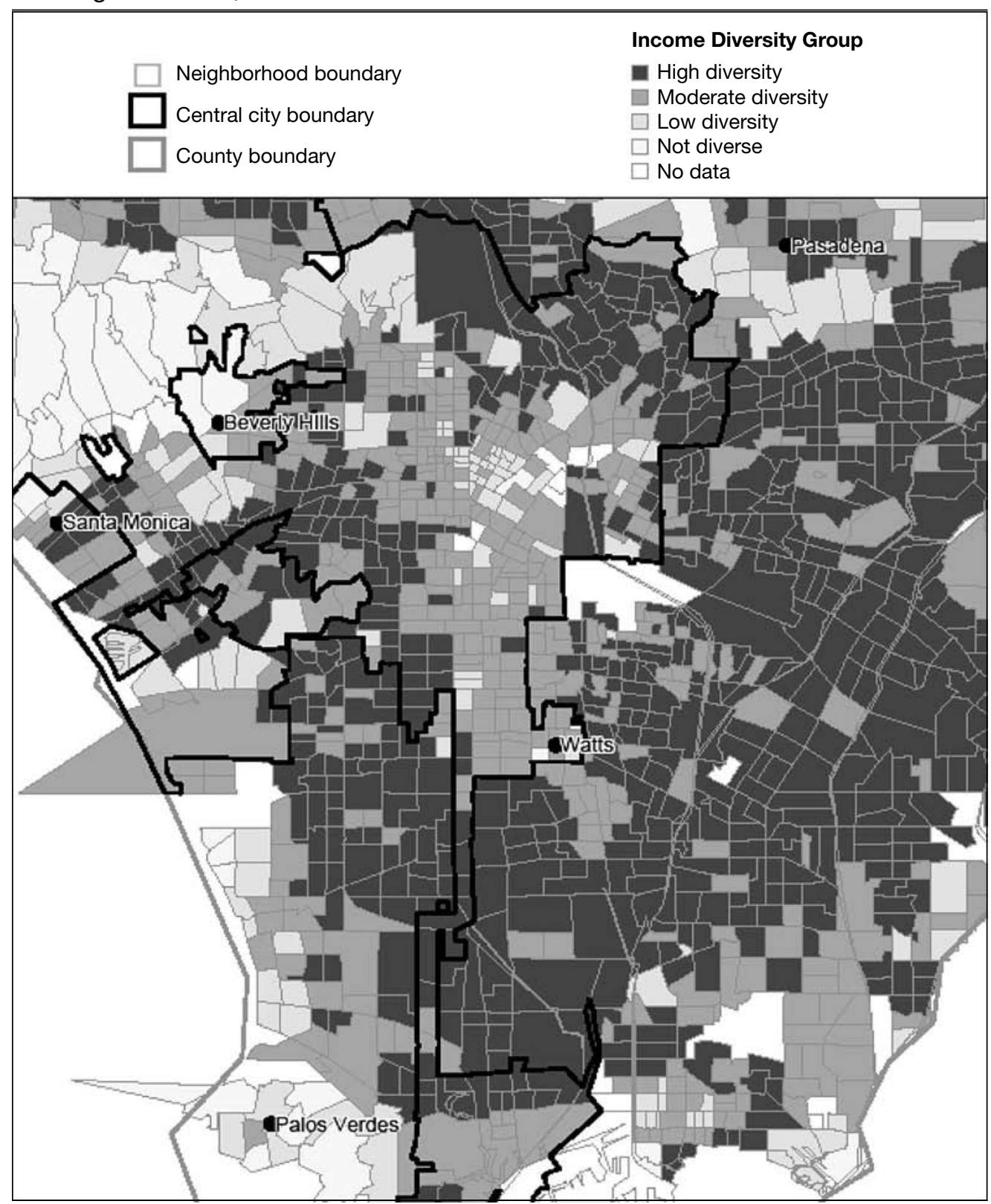

PMSA = primary metropolitan statistical area. 


\section{Exhibit 3}

\section{New York PMSA, 2000}

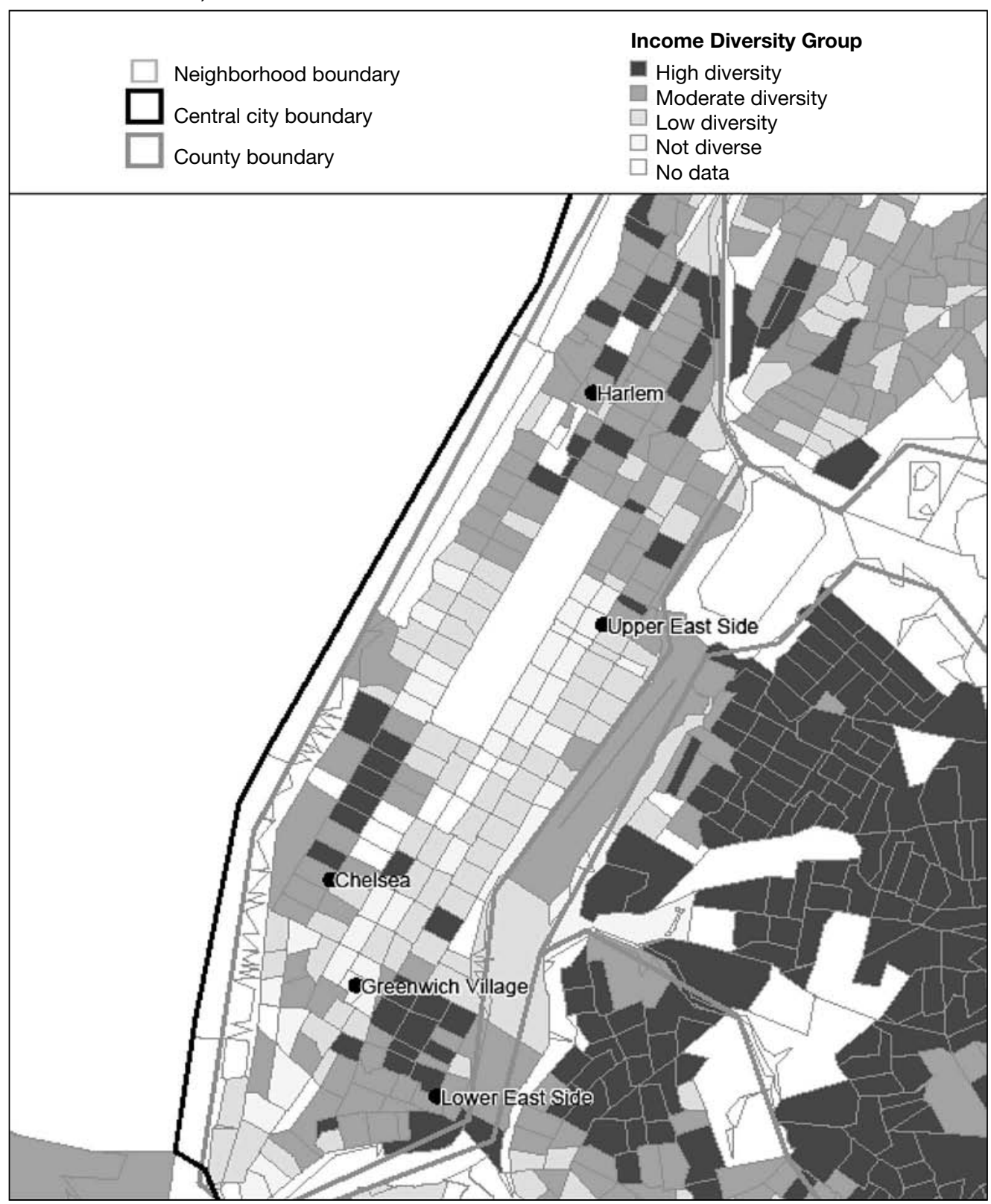

$P M S A=$ primary metropolitan statistical area . 


\section{Exhibit 4}

City of Chicago PMSA, 2000

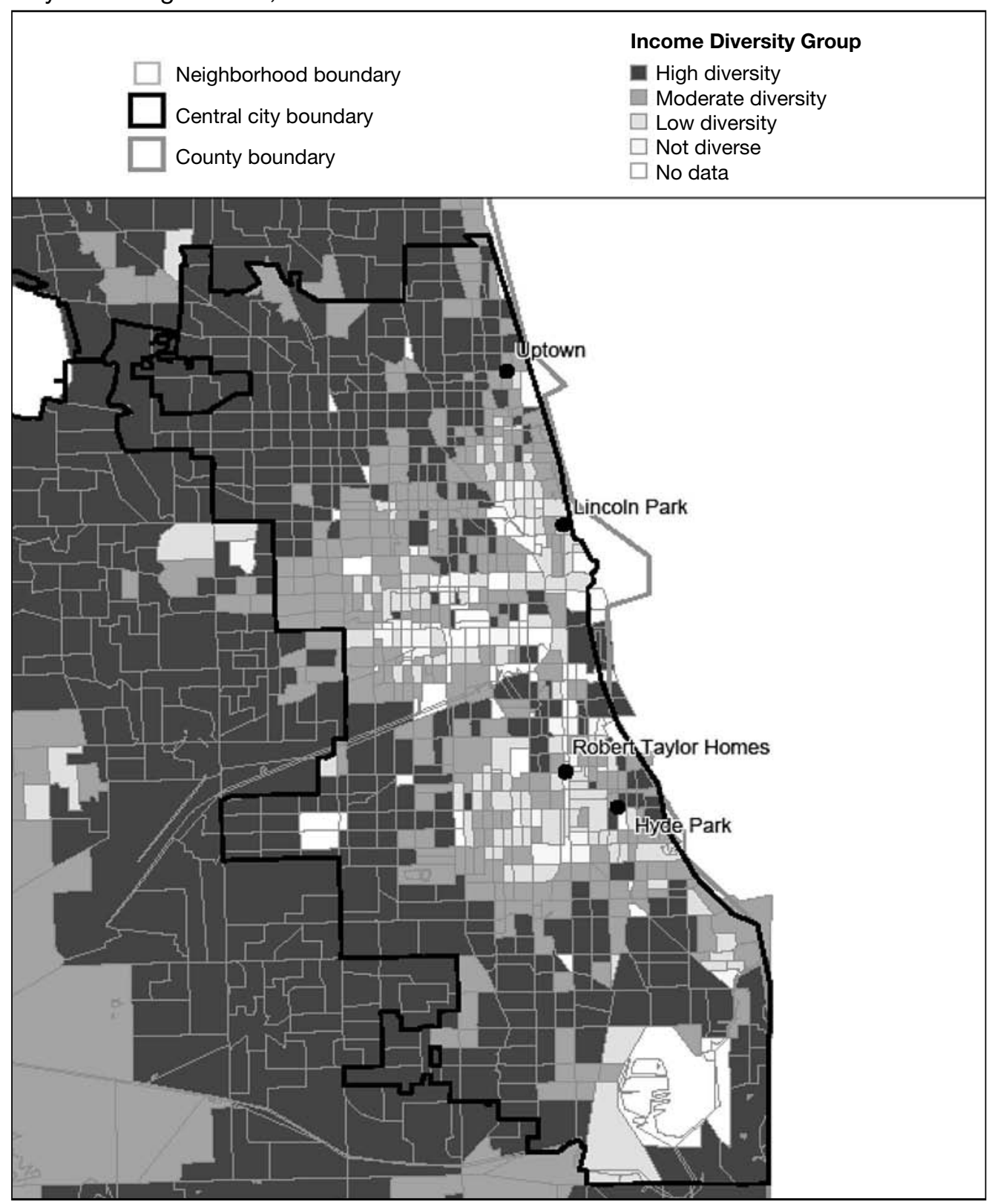




\section{Exhibit 5}

Washington, DC PMSA, 2000

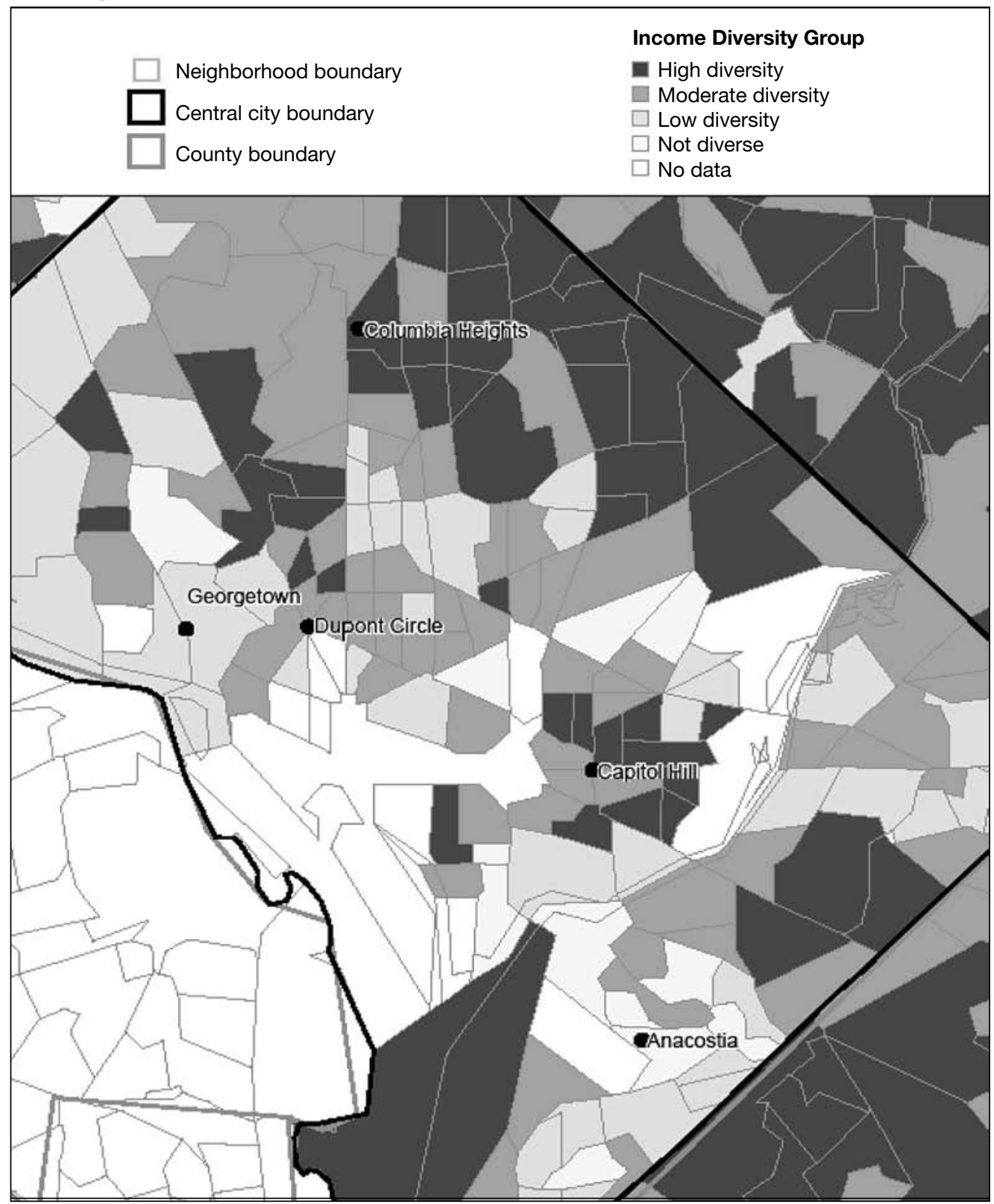

PMSA = primary metropolitan statistical area. 


\section{Exhibit 6}

Detroit PMSA, 2000

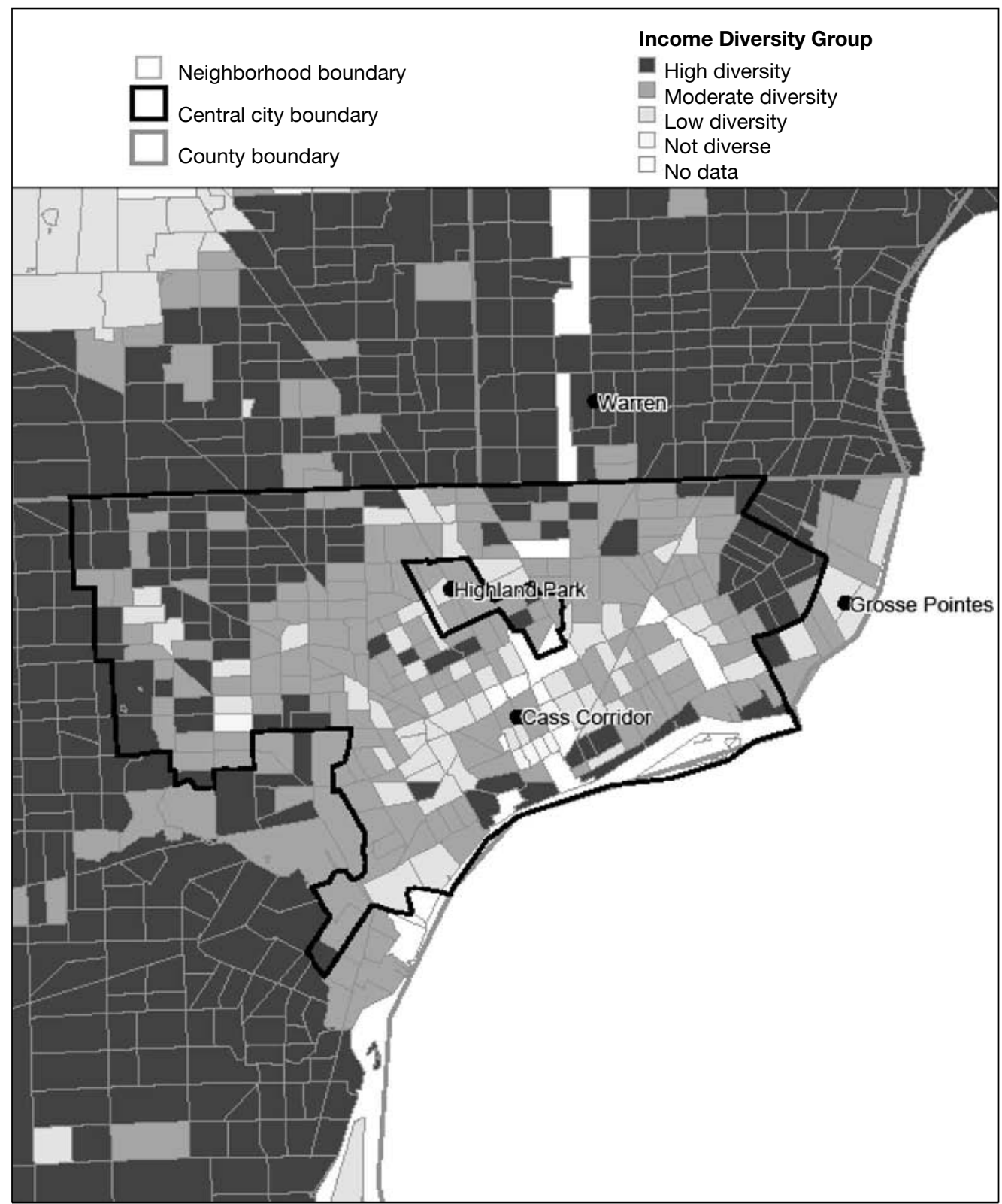

$P M S A=$ primary metropolitan statistical area . 
represented in areas within a few miles of the historical core. A ring of consistently high-diversity neighborhoods generally encompasses the aforementioned core region, sometimes punctuated by a few homogenous, HI enclaves. Closer to the exurban fringe, a larger share of not-diverse, HI and VHI neighborhoods is manifested.

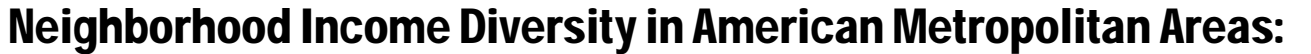

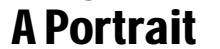

In overview, we found that the norm for neighborhood income diversity, as measured by mean entropy scores, although high, is decreasing over time, although this trend varies by neighborhood median income. In terms of neighborhood median income group, VLI, LI, HI, and VHI neighborhoods all became more diverse, but MI and HMI neighborhoods became less diverse since 1970. Most neighborhoods have high diversity, although their share has declined substantially since 1970.

\section{Neighborhood Income Diversity Patterns}

Before presenting our findings on income-diverse neighborhoods, we discuss overall neighborhood income distribution patterns. Based on census tract entropy scores, we found that the mean across all 100 metropolitan areas decreased from 0.91 in 1970 to 0.90 in 1980, 0.88 in 1990, and 0.87 in 2000 . Although an income entropy score above 0.8 is still considered very diverse by our standards, the trend shows a modest but steady decline during the 30 -year period. Such aggregates obscure interesting variations across neighborhood median-income groups, however, both in terms of variations in levels and in cyclical trends. The table in exhibit 7 shows the average neighborhood income entropy score between 1970 and 2000 by neighborhood median-income group; corresponding statistics for the individual metropolitan areas are presented in appendix A.

Regardless of the decade analyzed, metropolitan neighborhoods with medians at the extremes of the family-income distribution (VLI and VHI) are by far the least diverse in terms of income, with entropy scores ranging from 0.64 to 0.69 . Of course, this is to be expected given the mathematics of distribution characterized by extreme values for medians: for example, a very low median can be produced only if the vast majority of families have very low incomes. VLI neighborhoods are the least income-diverse, on average, followed closely by VHI neighborhoods. By contrast, MI and HMI neighborhoods are the most diverse, with entropy scores in the extremely high range of 0.96

\section{Exhibit 7}

Mean Family-Income Entropy Scores by HUD Neighborhood Group, 1970 to 2000, in the 100 Largest U.S. Metropolitan Areas

\begin{tabular}{lccccrc}
\hline $\begin{array}{c}\text { HUD Neighborhood } \\
\text { Group (Median Income) }\end{array}$ & $\mathbf{1 9 7 0}$ & $\mathbf{1 9 8 0}$ & $\mathbf{1 9 9 0}$ & $\mathbf{2 0 0 0}$ & $\begin{array}{r}\mathbf{1 9 7 0 - 2 0 0 0} \\
\text { Change }\end{array}$ & $\begin{array}{r}\text { Change as } \\
\text { Percent of } \\
\text { 1970 Value }\end{array}$ \\
Very low income & 0.658 & 0.651 & 0.636 & 0.662 & 0.004 & 0.61 \\
Low income & 0.884 & 0.889 & 0.886 & 0.887 & 0.003 & 0.34 \\
Moderate income & 0.975 & 0.976 & 0.972 & 0.969 & -0.006 & -0.62 \\
High moderate-income & 0.967 & 0.971 & 0.965 & 0.958 & -0.008 & -0.83 \\
High income & 0.875 & 0.892 & 0.886 & 0.884 & 0.009 & 1.03 \\
Very high income & 0.658 & 0.685 & 0.678 & 0.685 & 0.027 & 4.10 \\
\hline
\end{tabular}


to 0.98 . The most diverse neighborhoods (MI and HMI) have been dramatically decreasing in share since 1970, but the least diverse neighborhoods (VLI and VHI) have been increasing in share. This decrease in the most diverse neighborhoods explains the aggregate results we found-slight declines in overall neighborhood income diversity during the past 30 years.

The 30-year trends in entropy scores across neighborhood groups were inconsistent from decade to decade in all cases. Scores for LI and VHI neighborhoods fluctuated across the decades, yet showed an overall increase in diversity during the period. MI, HMI, and HI neighborhoods increased in diversity between 1970 and 1980, but their diversity declined after that. Although the decline overcame the increase for MI and HMI neighborhoods, resulting in an overall decrease, this was not the case for HI neighborhoods. Finally, although VLI neighborhoods experienced decreasing average diversity during the first two decades, the increase in average entropy scores between 1990 and 2000 completely overshadowed the decreases, resulting in a net increase during the 30-year period. Although average entropy scores portray an interesting overview of neighborhood income diversity, the following section looks at our diversity typology in a more disaggregated way and how it relates to the distribution of VLI families.

\section{The Incidence of Income-Diverse Neighborhoods in $\mathbf{2 0 0 0}$}

Turning now to the main focus of our study, we find that two-thirds of neighborhoods in the 100 largest U.S. metropolitan areas have high diversity in 2000 by our definition; see exhibit 8 and appendix A for results for individual metropolitan areas. This remarkable finding probably belies the conventional wisdom. Nevertheless, we would argue that this finding is not an artifact of our definition. We noted previously that our definition corresponds with common sense: if a neighborhood has at least five of the six HUD-specified income groups comprising at least one-sixth of the total, it can fairly be described as having high diversity Moreover, we reiterate that previous studies commonly find that most neighborhoods have high-income diversity as well, even though a variety of definitions of "highly diverse" has been employed. Considerably more income diversity exists within many neighborhoods than most people likely realize, despite the fact (as noted by Ioannides and Seslen, 2002) that there is less diversity of housing values. This scenario can easily arise, for example, by families aging in place, paying off their mortgages, and retiring at much lower income levels than currently earned by their younger neighbors in identical houses. Nevertheless, we acknowledge that our geographic unit of observation in this study—the census tract—may be larger than what most people commonly conceive of as their neighborhood. As such, our measures may be encompassing more diversity than is present at a smaller spatial scale.

\section{Changes in Patterns of Neighborhood Income Diversity Since 1970}

The table in exhibit 8 presents the 1970-to-2000 change in share of neighborhoods by diversity group. Although predominant, highly income-diverse neighborhoods decreased as a share of all metropolitan neighborhoods between 1970 and 2000 by 13.1 percentage points (16.6 percent). By contrast, the shares of all other groups increased. Moderate-diversity neighborhoods experienced the largest growth in share ( 8.7 percentage points) during the same period and by 2000 accounted for one-fourth of all neighborhoods. When we combine the moderate-diversity and high-diversity groups under our income-diverse rubric, the result is a net decline in share since 1970 of 4.4 per- 


\section{Exhibit 8}

Distribution of Neighborhoods by Diversity Group, 1970 to 2000, in the 100 Largest U.S. Metropolitan Areas*

\begin{tabular}{lrrrr}
\hline & $\begin{array}{c}\text { Not } \\
\text { Diverse }\end{array}$ & $\begin{array}{c}\text { Low } \\
\text { Diversity }\end{array}$ & $\begin{array}{c}\text { Moderate } \\
\text { Diversity }\end{array}$ & $\begin{array}{c}\text { High } \\
\text { Diversity }\end{array}$ \\
1970 & 0.6 & 4.0 & 16.1 & 79.3 \\
1980 & 1.1 & 5.7 & 18.8 & 74.3 \\
1990 & 1.8 & 7.7 & 22.0 & 68.4 \\
2000 & 1.4 & 7.6 & 24.8 & 66.2 \\
Change, 1970-2000 & 0.8 & 3.6 & 8.7 & -13.1 \\
Change as percent of 1970 value & 140.63 & 90.72 & 54.04 & -16.56 \\
\hline
\end{tabular}

${ }^{*}$ Figures shown are percentages; first four rows each total 100.

Note: Not-diverse neighborhoods are defined as having an entropy score less than 0.48 . Low-diversity neighborhoods have a diversity score equal to or greater than 0.48 but less than 0.69 . Moderate-diversity neighborhoods have an entropy score equal to or greater than 0.69 but less than 0.87 . High-diversity neighborhoods have an entropy score equal to or greater than 0.87 .

centage points. Although the combination of low-diversity and not-diverse neighborhoods comprised only 9 percent of the nation's metropolitan neighborhoods in 2000, their share was 4.4 percentage points higher than in 1970 .

The decade of the 1990s brought with it some interesting modifications to previous trends in neighborhood income diversity. Low-diversity and not-diverse neighborhoods, although increasing their share between 1970-to-1980 and 1980-to-1990, experienced slight reversals during the past decade. Although moderate-diversity neighborhoods increased and high-diversity neighborhoods decreased during each decade, their combined total reached its low point in 1990 and experienced a very slight rebound during the 1990s. This trend of decreasing neighborhood income diversity until 1990 was mirrored in the overall distribution of family income across our metropolitan areas, with a slight increase in overall income diversity occurring between 1990 and 2000. Thus, although America's period of unprecedented economic growth arguably countered the trend of declining neighborhood diversity of the previous 20 years, it was not able to completely overcome the loss.

The aforementioned changes in the patterns of neighborhood income diversity must be viewed, of course, in the context of concurrent changes in the overall distribution of family incomes in the metropolitan areas in question. In exploratory multivariate work, we identified the entropy of the metropolitanwide family-income distribution as the more important explanatory (although by no means the only) correlate of changes in the share of a metropolitan area's neighborhoods that were highly income diverse. ${ }^{13}$ These metropolitanwide-income entropy indices are presented for individual metropolitan areas in appendix A.

\footnotetext{
${ }^{13}$ Regression results available from first author, George C. Galster; also see Galster and Booza (2007) and Watson (2007).
} 


\section{Family-Income Distributions Across Neighborhoods With Different Income Diversity}

The table in exhibit 9 shows the percentage distribution of family-income group by neighborhood diversity group. ${ }^{14}$ The results show that not-diverse and low-diversity neighborhoods consist of, on average, roughly one-half VHI families and one-fourth VLI families. This portrait reinforces one painted earlier: the least diverse neighborhoods in American metropolitan areas typically are those where the broad range of families (MI, HMI) is virtually absent. Our other two diversity groups, moderate-diversity and high-diversity neighborhoods, present progressively more income mixing. Although VLI families continue to account for one-fourth of families in moderate-diversity neighborhoods, the representation of VHI families drops to one-third. In high-diversity neighborhoods, the VLI family share represents 19 percent and VHI families represent less than one-fourth of the total.

In addition to analyzing aggregate changes in diversity groups, we were also interested in understanding how diversity has changed in VLI neighborhoods. The table in exhibit 10 shows the distribution of neighborhoods predominantly occupied by VLI families by neighborhood income diversity group.

Exhibit 10 shows that slightly more than one-half of VLI neighborhoods in 2000 had moderate diversity, with the remainder containing little or no income diversity. During the entire 30-year period, the distribution of VLI neighborhoods has been moving in two directions, although different decades have brought reversals in each. The shares of both not-diverse and moderate-diversity VLI neighborhoods have risen, but the share of low-diversity neighborhoods has fallen between 1970 and 2000. Although the mean entropy score for VLI neighborhoods showed an increase in diversity, it is obvious that not all VLI neighborhoods became more diverse. Rather, it was the increasing share of moderate-diversity VLI neighborhoods that produced this aggregate mean result.

\section{Exhibit 9}

Distribution of Family-Income Mix by Neighborhood Diversity Groups, 2000, in the 100 Largest U.S. Metropolitan Areas*

\begin{tabular}{lcccc}
\hline \multirow{2}{*}{ HUD Family-Income Group } & \multicolumn{3}{c}{ Neighborhood Diversity Group } \\
\cline { 2 - 5 } & $\begin{array}{c}\text { Not } \\
\text { Diverse }\end{array}$ & $\begin{array}{c}\text { Low } \\
\text { Diversity }\end{array}$ & $\begin{array}{c}\text { Moderate } \\
\text { Diversity }\end{array}$ & $\begin{array}{c}\text { High } \\
\text { Diversity }\end{array}$ \\
Very low income & 24.0 & 22.6 & 23.6 & 19.3 \\
Low income & 5.3 & 9.8 & 15.3 & 19.5 \\
Moderate income & 2.7 & 5.4 & 8.8 & 12.9 \\
High moderate income & 2.8 & 5.1 & 7.9 & 11.5 \\
High income & 4.5 & 7.8 & 10.4 & 13.2 \\
Very high income & 60.7 & 49.3 & 34.0 & 23.6 \\
\hline
\end{tabular}

${ }^{*}$ Figures shown are percentages; columns total 100.

\footnotetext{
${ }^{14}$ We summed all families in each diversity group and used this sum as the denominator for each family income group to get the percentages shown in exhibit 9 .
} 


\section{Exhibit 10}

Distribution of Very Low-Income Neighborhoods by Neighborhood Income Diversity Group, 1970 to 2000, in the 100 Largest U.S. Metropolitan Areas*

\begin{tabular}{ccccc}
\hline $\begin{array}{c}\text { Very Low-Income (Median) Neighborhoods' } \\
\text { Percentage Distribution in- }\end{array}$ & $\begin{array}{c}\text { Not } \\
\text { Diverse }\end{array}$ & $\begin{array}{c}\text { Low } \\
\text { Diversity }\end{array}$ & $\begin{array}{c}\text { Moderate } \\
\text { Diversity }\end{array}$ & $\begin{array}{c}\text { High } \\
\text { Diversity }\end{array}$ \\
1970 & 6.3 & 48.7 & 45.1 & 0.0 \\
1980 & 9.7 & 43.2 & 47.1 & 0.0 \\
1990 & 12.2 & 43.9 & 43.9 & 0.0 \\
2000 & 7.9 & 41.3 & 50.8 & 0.0 \\
\hline
\end{tabular}

${ }^{*}$ Figures shown are percentages; rows each total 100.

Note: Not-diverse neighborhoods are defined as having an entropy score less than 0.48. Low-diversity neighborhoods have a diversity score equal to or greater than 0.48 but less than 0.69 . Moderate-diversity neighborhoods have an entropy score equal to or greater than 0.69 but less than 0.87 . High-diversity neighborhoods have an entropy score equal to or greater than 0.87.

Note: $A$ very low-income neighborhood is one where median family income is less than 50 percent of the metropolitan median.

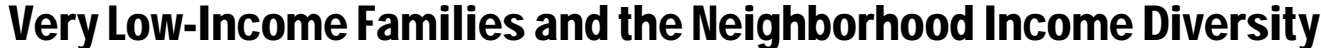

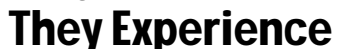

In this section we examine the distribution of VLI families across neighborhood groups categorized by income diversity and median incomes and by the families' degree of exposure to other income groups. This empirical issue is important because, as we discuss further in the following text, a variety of studies suggests that social interactions among neighbors will depend on their socioeconomic differences. Thus the networking and social capital that VLI families may gain from their neighborhood will depend on which other groups are present (Galster et al., 2008; Galster and Booza, 2007). We note at the outset that the terms "very low-income neighborhoods" and "very low-income families' neighborhoods" are not tautologically related. Because the former is defined by the median of the family-income distribution in a neighborhood, many varieties of income distributions can be subsumed within the same group. Similarly, VLI families may live in a wide variety of neighborhoods categorized by median incomes; a small share may actually live in VLI neighborhoods.

\section{Distribution of VLI Families Across Neighborhood Diversity Groups}

The table in exhibit 11 presents the distribution of VLI families by neighborhood diversity group. At least two-thirds of VLI families resided in high-diversity neighborhoods during the 1970-to-2000 period. Roughly one-fifth resided in moderate-diversity neighborhoods, and approximately one-tenth resided in low-diversity or not-diverse ones. The VLI share in high-diversity neighborhoods is substantially lower in 2000 than in 1970, however; the pattern is opposite for all other diversity groups. In particular, the share of VLI in high-diversity neighborhoods fell more than 10 percentage points (14 percent) in the past 30 years, from 75.3 to 65.0 . 


\section{Exhibit 11}

Distribution of Very Low-Income Families by Neighborhood Diversity Group, 1970 to 2000, in the 100 Largest U.S. Metropolitan Areas*

\begin{tabular}{ccccc}
\hline $\begin{array}{c}\text { Very Low-Income Families' } \\
\text { Percentage Distribution in- }\end{array}$ & $\begin{array}{c}\text { Not } \\
\text { Diverse }\end{array}$ & $\begin{array}{c}\text { Low } \\
\text { Diversity }\end{array}$ & $\begin{array}{c}\text { Moderate } \\
\text { Diversity }\end{array}$ & $\begin{array}{c}\text { High } \\
\text { Diversity }\end{array}$ \\
1970 & 0.5 & 4.8 & 19.4 & 75.3 \\
1980 & 1.4 & 6.5 & 21.0 & 71.2 \\
1990 & 2.0 & 8.2 & 23.9 & 65.8 \\
2000 & 1.1 & 7.2 & 26.7 & 65.0 \\
\hline
\end{tabular}

*Figures shown are percentages; rows total 100.

\section{Income Groups in Neighborhoods With VLI Median Income}

We next address the question: What higher income groups are typically present in neighborhoods occupied by VLI families? This question really has two parts. First, we are asking what families live in neighborhoods in which median family incomes designate them as VLI and, second, we are asking about the income distribution of all neighborhoods in which VLI families reside. To answer the first part we present exhibit 12 , a table that shows the distribution of family-income groups in VLI neighborhoods from 1970 to 2000.

Data presented in exhibit 12 show that VLI neighborhoods are made up of mostly VLI families (59 percent, on average), with LI families constituting roughly another one-fifth and the remainder divided evenly across the other income groups. As for their trends over time, the share of VLI families in VLI neighborhoods peaked in 1990, with a small drop by 2000, but showed continued growth in LI neighborhoods through 2000.

As for other income groups in these neighborhoods, the share of VHI families experienced growth of 2.1 percentage points in VLI neighborhoods during the 30-year period. This remarkable rise equated to an increase of 101,942 VHI families across our sample. We suspect that this result has been produced by recent redevelopment projects in core neighborhoods previously occupied by VLI, but it is beyond the scope of this study to test this empirically. By contrast, during the 30 years, MI families experienced a consistent decline in share in VLI neighborhoods, while the share of HMI families peaked for VLI neighborhoods in 1980, with declines since.

\section{Exhibit 12}

Distribution of Families by Income Group in Very Low-Income Neighborhoods, 1970 and 2000, in the 100 Largest U.S. Metropolitan Areas*

\begin{tabular}{lrrrr}
\hline \multirow{2}{*}{ HUD Family-Income Group } & \multicolumn{3}{c}{ Very Low-Income (Median) Neighborhoods } \\
\cline { 2 - 5 } & $\mathbf{1 9 7 0}$ & $\mathbf{1 9 8 0}$ & $\mathbf{1 9 9 0}$ & $\mathbf{2 0 0 0}$ \\
Very low income & 57.9 & 59.7 & 60.7 & 58.9 \\
Low income & 22.8 & 18.9 & 18.2 & 19.3 \\
Moderate income & 8.1 & 7.8 & 7.5 & 7.5 \\
High moderate income & 4.7 & 5.1 & 4.9 & 4.7 \\
High income & 3.1 & 4.2 & 4.3 & 4.1 \\
Very high income & 3.4 & 4.3 & 4.4 & 5.5 \\
\hline
\end{tabular}

\footnotetext{
"Figures shown are percentages; columns total 100.
} 


\section{Median Neighborhood Incomes of VLI Families}

Thus far in this study, we have shown that by 2000 in the 100 largest U.S. metropolitan areas, 20 percent of all families in the United States were considered VLI, and 65 percent of VLI families lived in high-diversity neighborhoods. We have yet to show, however, the neighborhood income groups in which most VLI families live. These statistics can be found in exhibit 13, a table that shows the distribution of VLI families across neighborhood income groups from 1970 to 2000. According to these data, in 2000 most VLI families (roughly 60 percent) lived in neighborhoods where the median family incomes qualify them as LI and MI, while only 15 percent lived in VLI neighborhoods.

Comparing trends over time, there has been a mix of both unbroken trends during the 30-year period and decade-to-decade fluctuations. The most obvious change is the continual decline in the share of VLI families who reside in MI and HMI neighborhoods. A further unbroken trend is the increased shares of VLI families in HI and VHI neighborhoods. As the extremes of the neighborhood distribution increase disproportionately, we would expect to see increased shares of families in these groups; however, this was not the case with the observed changes in shares at the lower end of the neighborhood income distribution. VLI families did generally increase their percentages living in VLI neighborhoods, but not consistently over time. The shares of all VLI families living in VLI neighborhoods peaked in 1990. Similar volatility is shown by the share of VLI families residing in LI neighborhoods, which was on the decline between 1970 and 1980, reversed itself for 1990, and experienced such a rise by 2000 that the earlier decline was completely overridden.

\section{Exhibit 13}

Distribution of VLI Families by Neighborhood Median Income Group, 1970 to 2000 in the 100 Largest U.S. Metropolitan Areas*

\begin{tabular}{ccccccc}
\hline $\begin{array}{c}\text { Very Low-Income } \\
\text { Families' Percentage } \\
\text { Distribution in- }\end{array}$ & $\begin{array}{c}\text { Very Low } \\
\text { Income }\end{array}$ & Low Income & $\begin{array}{c}\text { Moderate } \\
\text { Income }\end{array}$ & $\begin{array}{c}\text { High } \\
\text { Moderate } \\
\text { Income }\end{array}$ & $\begin{array}{c}\text { High } \\
\text { Income }\end{array}$ & $\begin{array}{c}\text { Very High } \\
\text { Income }\end{array}$ \\
1970 & 8.1 & 33.5 & 32.4 & 18.3 & 6.2 & 1.5 \\
1980 & 14.2 & 31.5 & 27.4 & 17.8 & 7.2 & 2.0 \\
1990 & 17.4 & 32.5 & 25.3 & 14.5 & 7.5 & 2.8 \\
2000 & 15.0 & 36.7 & 23.2 & 13.5 & 7.7 & 3.8 \\
\hline
\end{tabular}

${ }^{*}$ Figures shown are percentages; rows total 100.

\section{Exposure of VLI Families to Other Income Groups}

Another research question considers the average income mixture in the neighborhoods in which VLI families reside. In the previous section we focused on the share of families comprising each neighborhood group and how families were distributed across neighborhood groups. In this section we further explore the mixture of income groups by using an exposure index to describe the residential patterns of VLI families with regard to other income groups.

The table in exhibit 14 reports the exposure of VLI families to every income group, including VLI. An entry in any row can be interpreted as the proportion of the particular income group (shown 
in the corresponding column) that resides, on average, in the census tract occupied by the typical VLI (row for a specific year) family in the year shown. Equivalently, it can be interpreted as the probability that a member of the particular income group will reside in a VLI family's neighborhood. The sum across any row equals one and represents the full distribution of exposures of VLI families. The joint VLI/VLI cell represents intragroup exposure. This intragroup exposure can be interpreted as the isolation of VLI families: the percentage of the average VLI family's neighbors who are also VLI.

Exhibit 14 shows that, by 2000, VLI families were about as exposed to other families in their same income group as they were to LI and VHI families: from 20 percent to 23 percent in each case. The remaining three income groups accounted for the remaining one-third of all of VLIs' exposure. Although consistent with findings above, the substantial and perhaps unexpected exposure of VLI to VHI families is a subject worthy of further discussion below.

Exposure patterns for VLI families have changed considerably over time. The isolation of VLI families is lower in 2000 than in 1970, the result of a large drop between 1990 and 2000, following a small increase between 1980 and 1990. Their exposure to LI families has remained stable during the entire period. It is the increase in exposure to VHI families that is of special interest to us and will be the subject of further discussion in the following text. Whereas we saw the isolation of VLI families peak in 1990 and then decrease, we saw the reverse with exposure to VHI families - they declined up until 1980, slightly increased by 1990, and then showed a large gain during the 1990s. The net result was that VLI families in 2000 had almost a 4-percentage-point greater exposure to VHI families than in 1970, representing a 21-percent increase in exposure. Thus, since 1970, VLI families in our 100 largest U.S. metropolitan areas experienced a decrease in isolation and increased exposure to all other groups, especially VHI families.

\section{Exhibit 14}

Interincome Group Exposure Indexes for Very Low-Income Families, by FamilyIncome Group, 1970 to 2000, in the 100 Largest U.S. Metropolitan Areas

\begin{tabular}{ccccccc}
\hline \multirow{2}{*}{$\begin{array}{c}\text { Very Low-Income } \\
\text { Families' Exposure to: }\end{array}$} & $\begin{array}{c}\text { Very Low } \\
\text { Income }\end{array}$ & Low Income & $\begin{array}{c}\text { Moderate } \\
\text { Income }\end{array}$ & $\begin{array}{c}\text { High } \\
\text { Moderate } \\
\text { Income }\end{array}$ & $\begin{array}{c}\text { High } \\
\text { Income }\end{array}$ & $\begin{array}{c}\text { Very High } \\
\text { Income }\end{array}$ \\
1970 & 0.307 & 0.202 & 0.113 & 0.092 & 0.100 & 0.186 \\
1980 & 0.292 & 0.197 & 0.125 & 0.107 & 0.114 & 0.164 \\
1990 & 0.311 & 0.199 & 0.117 & 0.097 & 0.106 & 0.170 \\
2000 & 0.234 & 0.203 & 0.120 & 0.102 & 0.116 & 0.225 \\
\hline
\end{tabular}

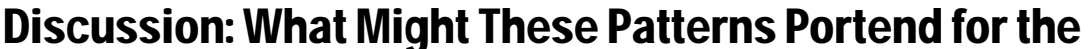 *}

In the foregoing empirical work we found that the 100 largest U.S. metropolitan areas across the country in 2000 were primarily composed of high-diversity neighborhoods (entropy scores above 0.69), although average entropy scores of neighborhood income diversity decreased slightly since 
1970. We found that a majority of neighborhoods with median incomes categorized as VLI fall in the high-diversity group, and a large majority of VLI families live in high-diversity neighborhoods. VLI families are similarly exposed to VLI, LI, and, remarkably, VHI families. These facts provide considerable nuance to the commonly accepted nostrum often associated with the concentrated poverty debate that the disadvantaged typically live in homogenously deprived neighborhoods. Trends since 1970, however, show that the share of all neighborhoods that are high diversity and the proportion of VLI families living in high-diversity neighborhoods have been declining steadily.

Our discussion here connects these core findings to issues related to a realm of the potential social consequences of neighborhood income diversity that have often been at the core of policymakers' concerns: enhancing upward socioeconomic mobility for the disadvantaged. Unfortunately, extant empirical and theoretical scholarship provides mixed messages about the degree to which impacts may ensue from the neighborhood income diversification trends we are witnessing and whether they ultimately will prove beneficial to VLI families.

Empirically, several sophisticated multivariate statistical models have found that higher shares of affluent (instead of low-income) neighbors are associated with various positive outcomes for VLI families and their children, although they cannot identify the underlying mechanism of such correlations; see Chase-Lansdale et al. (1997), Crane (1991), Duncan, Connell, and Klebanov (1997), and Kohen et al. (2002). Nevertheless, Galster et al. (2008) find that it is the presence of middle-income (not high-income) neighbors that proves most efficacious in boosting the incomes of disadvantaged adult neighbors. This finding suggests that the increasingly extreme income differences among neighbors that we are witnessing in American neighborhoods are less likely to encourage the upward socioeconomic mobility of VLI families than if they were increasingly exposed to MI families. This suggestion is consistent with skeptical reviews of the evidence on potential benefits of mixed-income neighborhoods for the disadvantaged (Joseph, 2006; Joseph, Chaskin, and Webber, 2006).

The key for predicting socioeconomic mobility impacts is the mechanism through which income diversity within neighborhoods affects VLI residents. Neighborhood conditions in general are seen as a crucial component of what analysts now commonly describe as life chances being influenced by the "geography of opportunity" (Briggs 2005; Galster and Killen, 1995). It is crucial, however, to distinguish three groups of potential neighborhood effects: ${ }^{15}(1)$ local resources and institutions, (2) networking, and (3) role modeling and social control. It first may be argued that increasing numbers of $\mathrm{HI}$ and VHI neighbors will aid the less well off who live nearby because the former will financially support a stronger set of local institutions (both secular and religious), exert superior political clout in ensuring the delivery of the highest quality municipal services and facilities (including public schools), and create demands for local retail establishments that will generate new job opportunities for those of modest skills (Wilson, 1987). Although this argument may be valid, empirical validation has not been forthcoming, complicated as it is by challenges in measurement and the likelihood of nonlinear, threshold-like relationships (Quercia and Galster, 1997).

\footnotetext{
${ }^{15}$ There also may be other salutary mechanisms for opportunity enhancement at work that do not involve intraneighborhood processes, such as improvements in neighborhood access to jobs or the reduction of place-based stigmatization.
} 
Second, it may be argued that social scientists have hypothesized many potential varieties of social interactions among neighbors of different economic statuses that could serve to enhance the lower status group's opportunities for upward socioeconomic mobility (Ellen and Turner, 2003; Gephardt, 1997). Granovetter (2005), for example, has stressed the instrumental value of "weak ties" among networked acquaintances in supplying critical information about employment and other opportunities for social advancement. But such ties require certain kinds of social interactions among groups, and the existing evidence about the likelihood of such interactions among highly disparate income groups is not sanguine.

Many studies have capitalized on "natural experiments" involving public housing redevelopment, rent vouchers, or inclusionary zoning laws to create co-locations within neighborhoods of disparate income groups; see especially Rosenbaum (1995, 1991), Rosenbaum, Reynolds, and DeLuca (2002), Briggs (1998), Kleit (2005, 2002, 2001a, 2001b,), Schill (1997), Clampet-Lundquist (2004), Popkin, Harris, and Cunningham (2002), and Rosenbaum, Harris, and Denton (2003). In sum, these works consistently show that the social relationships among members of different (especially widely different) income groups are quite limited, even within the same neighborhood or housing complex. Members of the lower income group often do not take advantage of propinquity to broaden their weak ties and enhance the resource-producing potential of their networks, instead often restricting their networks to nearby members of their own group or to those remaining in the old neighborhood. This tendency suggests that social networking may be a powerful neighborhood force among members of a given group, but less so in an intergroup context. Thus, neighborhoods dominated by both VLI and VHI families are unlikely to be places where socioeconomic mobility is substantially enhanced by informally connecting VLI residents to resource-rich networks of their VHI neighbors.

So, is there any other reason to think that increasing exposure of VLI to VHI families may provide enhanced opportunities through other intraneighborhood social processes besides networking? The answer may be affirmative to the extent that the role model and social control mechanisms operate strongly, as has been argued by Rosenbaum (1991). Despite this argument, the evidence once again is indirect and inconclusive regarding this mechanism.

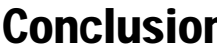

The current research set out to paint a portrait of income-diverse neighborhoods and the degree to which very low-income families experience them. We analyzed census tracts in the 100 largest metropolitan areas in the United States in 2000 and assessed with an entropy index how their number and share by diversity group have changed between 1970 and 2000. In addition, we looked at the particulars of income mix within such neighborhoods, with an eye toward better understanding the residential contexts to which VLI families are exposed.

Among our major descriptive findings, we found that in 2000 two-thirds of neighborhoods have high degrees of income diversity, but highly income-diverse neighborhoods decreased as a share of all neighborhoods during the 30-year period. No neighborhoods have high diversity if their median income falls below 50 percent of the AMI. VLI families constitute 19 percent of high-diversity neighborhoods' populations, on average, although the corresponding percentage is 24 percent 
for not-diverse neighborhoods. Two-thirds of VLI families live in high-diversity neighborhoods, although this share has fallen steadily and substantially since 1970. VLI families are increasingly being exposed to VHI neighbors; indeed the exposure to VHI families is approximately the same as exposure to other VLI families; however, VLI exposure to MI and HMI groups is declining correspondingly.

We have proposed that VLI families' increasing exposure to VHI (and decreasing exposure to MI) families raises important issues related to socioeconomic mobility. There are theoretical reasons to believe that this development may hold felicitous prospects for the well-being of the disadvantaged residents living in income-diverse neighborhoods; however, this outcome is by no means certain, as the empirical evidence indicates. This uncertainty suggests that scholars and policymakers should assume heightened vigilance regarding this phenomenon to ascertain whether it produces desirable or undesirable consequences.

Future research could well build upon our work by addressing the interaction of race/ethnicity and income by studying trends in neighborhoods that are diverse in both income and race/ethnicity (for example, Turner and Fenderson, 2006). In addition, although the current study and most previous studies have used the decennial census as the primary source of data, the Census Bureau's new American Community Survey, designed to be used as a replacement to the decennial long form questionnaire, will begin to produce census tract-level data on a rolling multiyear basis toward the end of this decade. Such a rich data set will enable researchers to test hypotheses and track changes on a more frequent and timely basis. In addition, this valuable and current database holds great promise for further illuminating the factors affecting the growth and/or contraction of income-diverse neighborhoods and the living arrangements of VLI families. Such knowledge will greatly contribute to future policy decisions. 


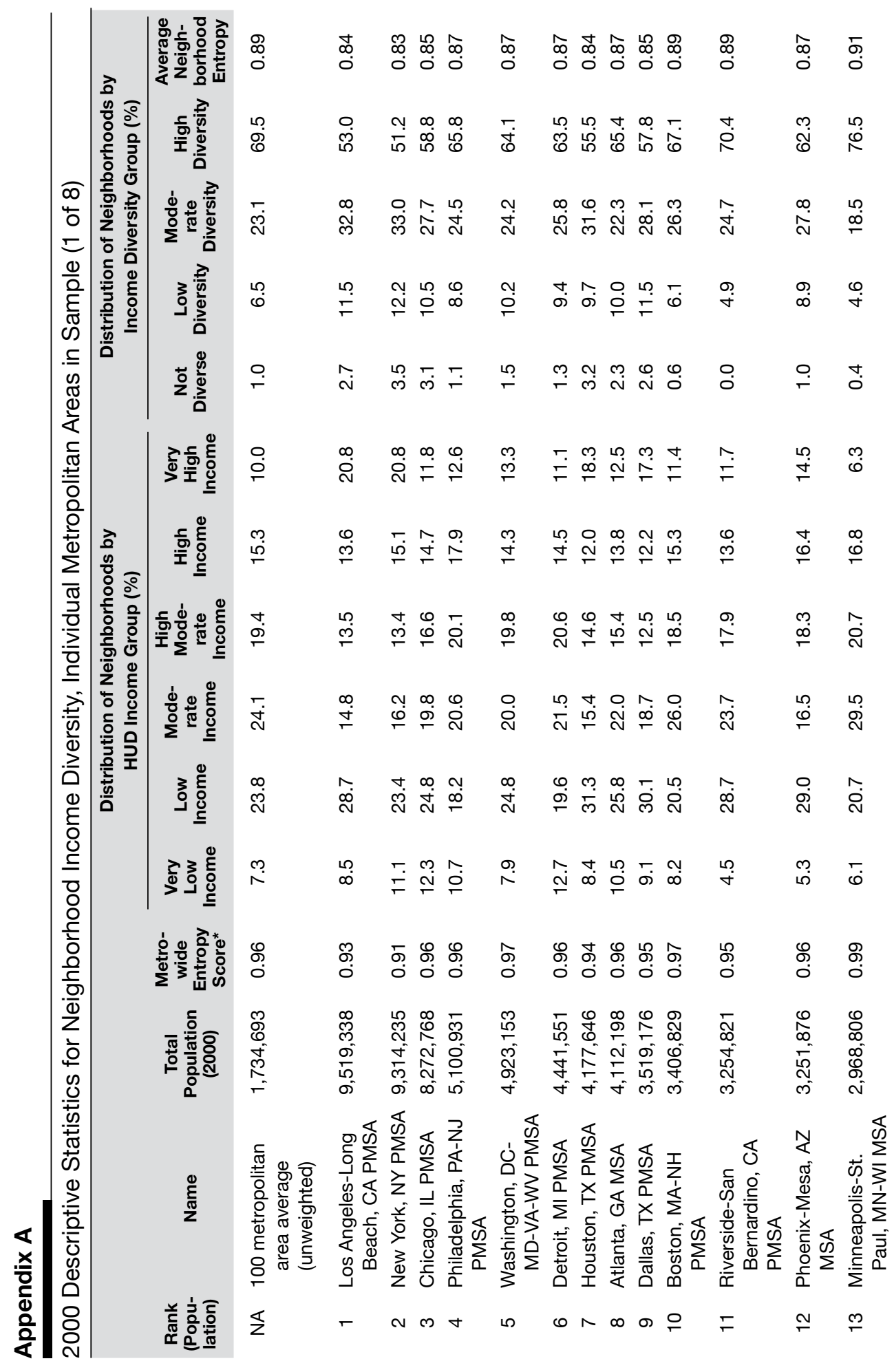




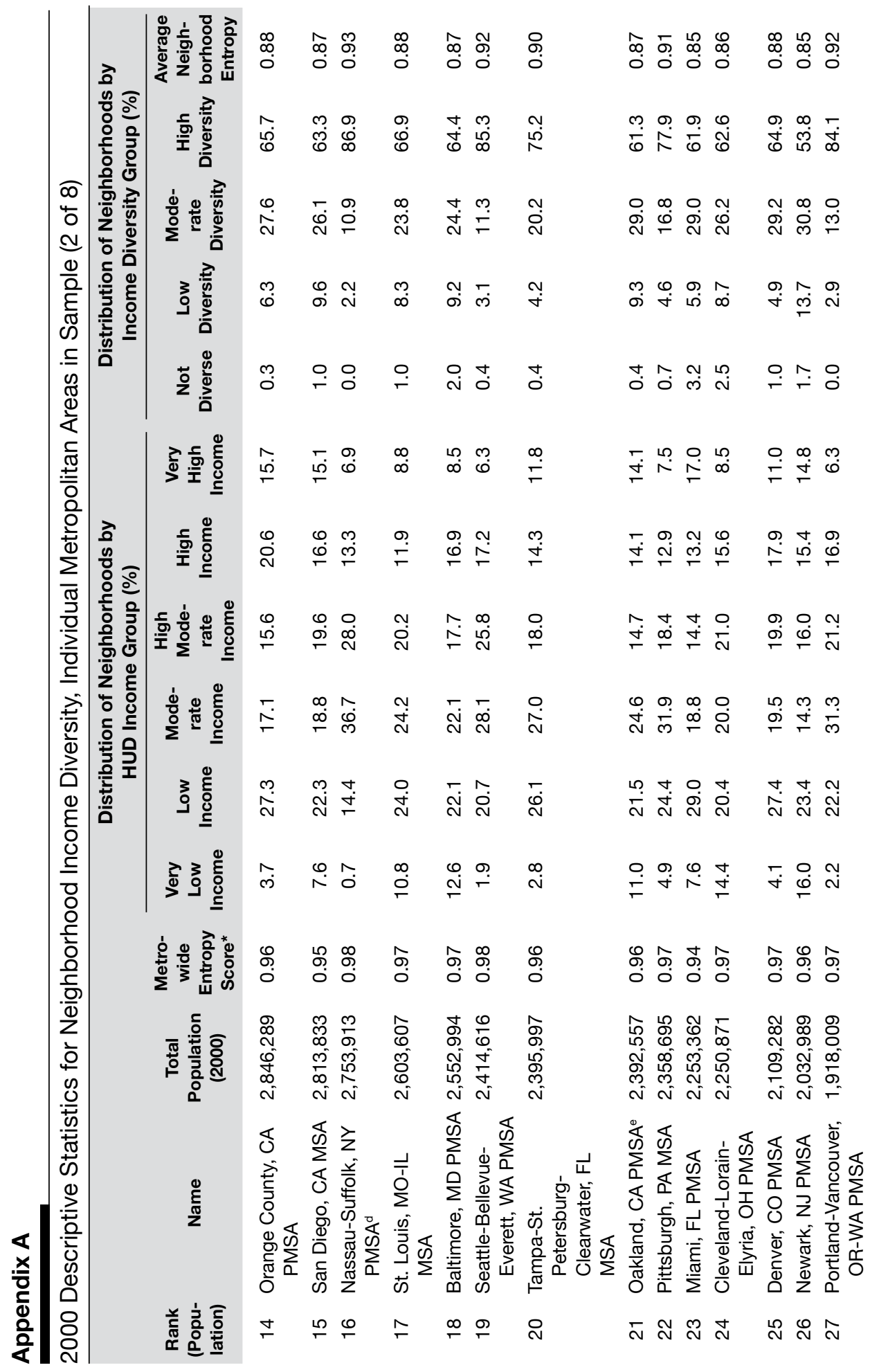




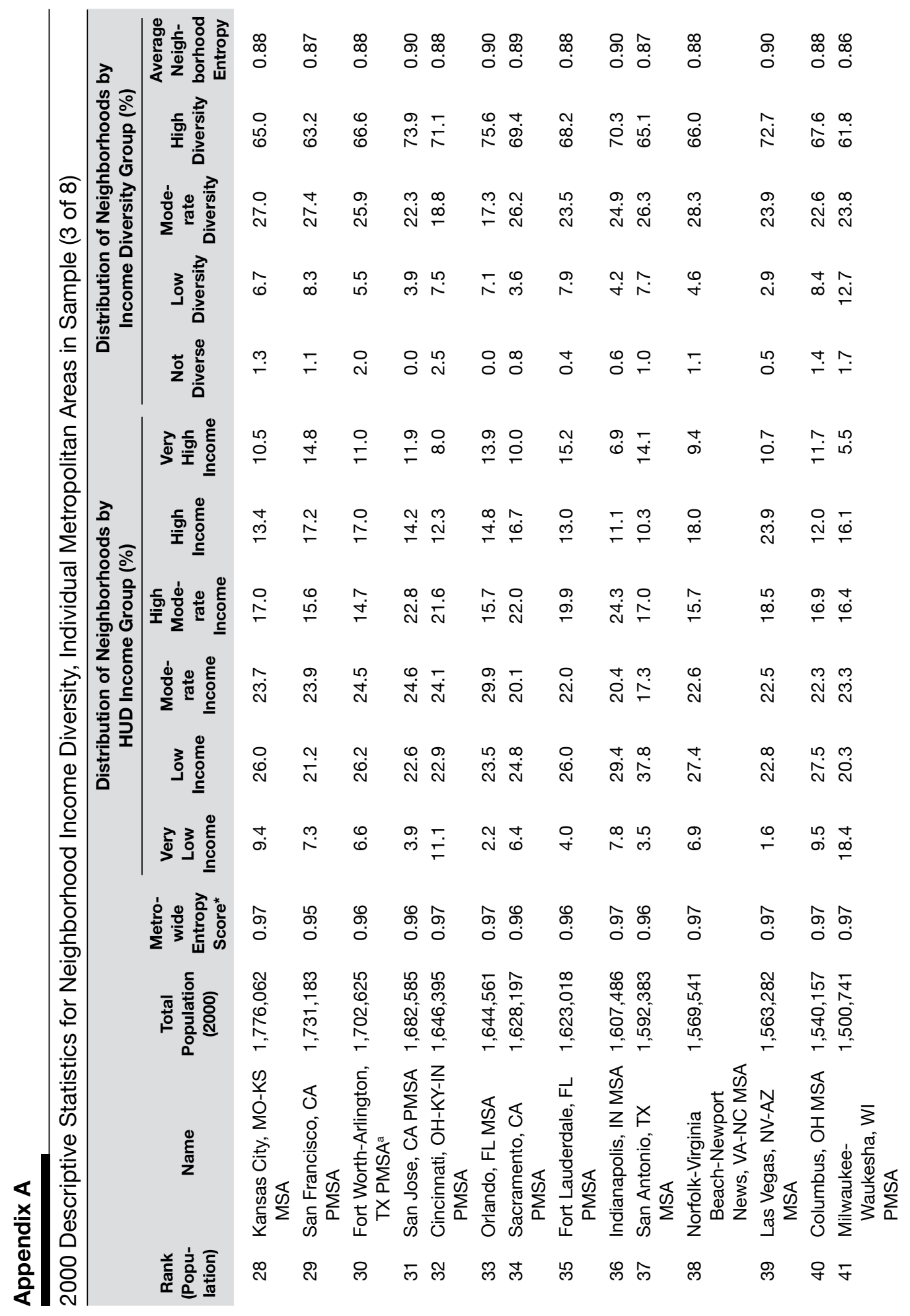




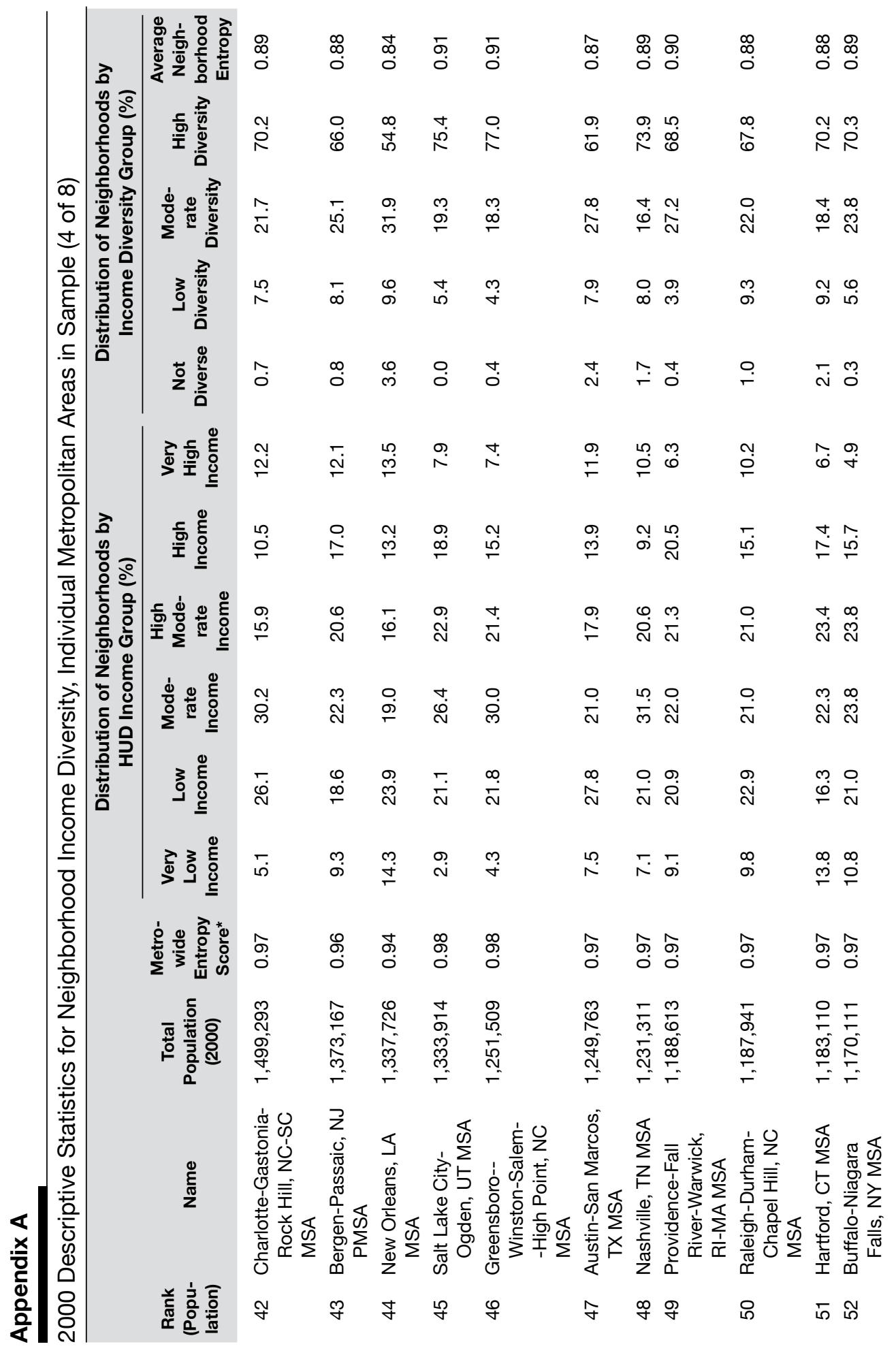




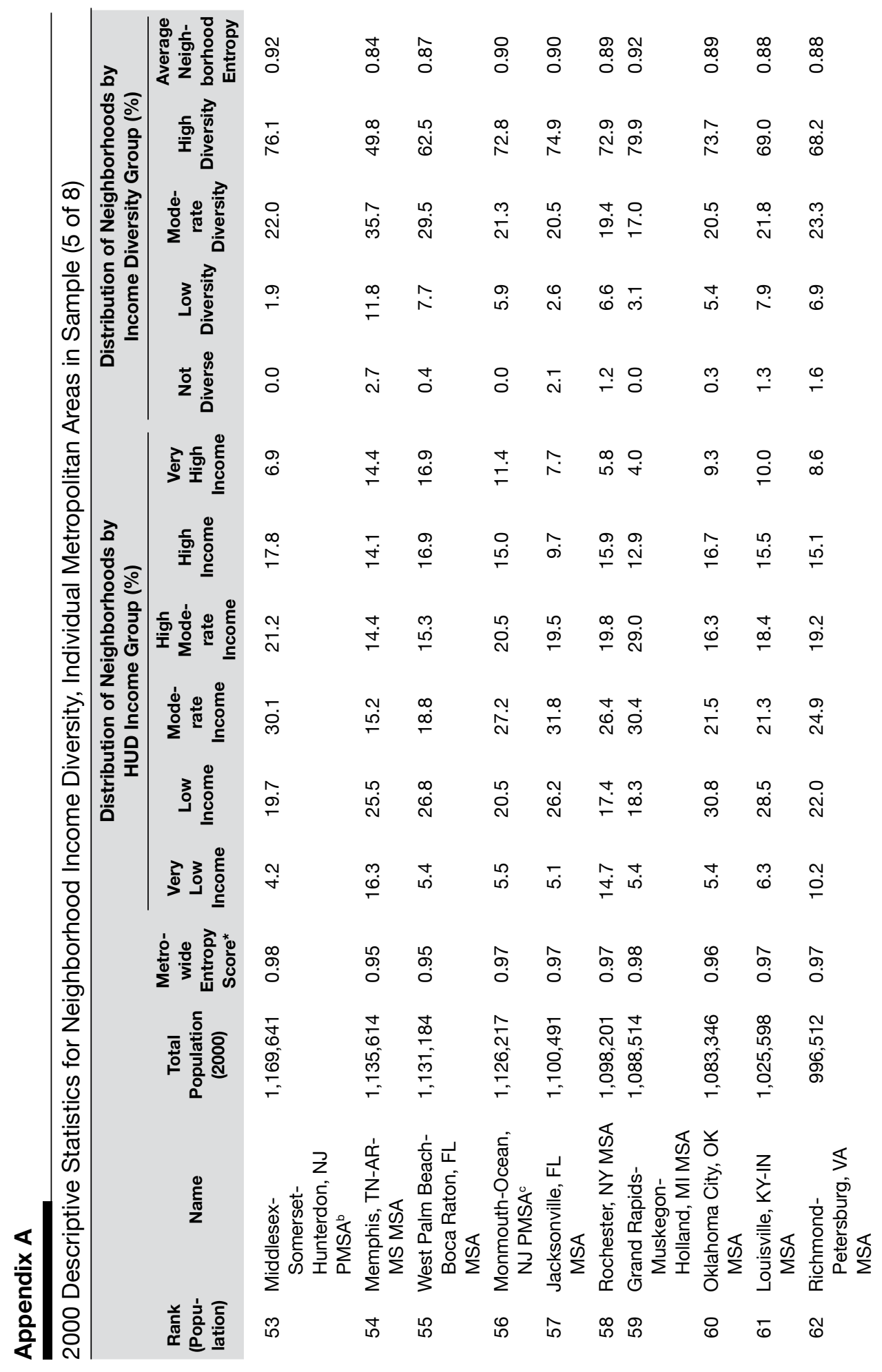




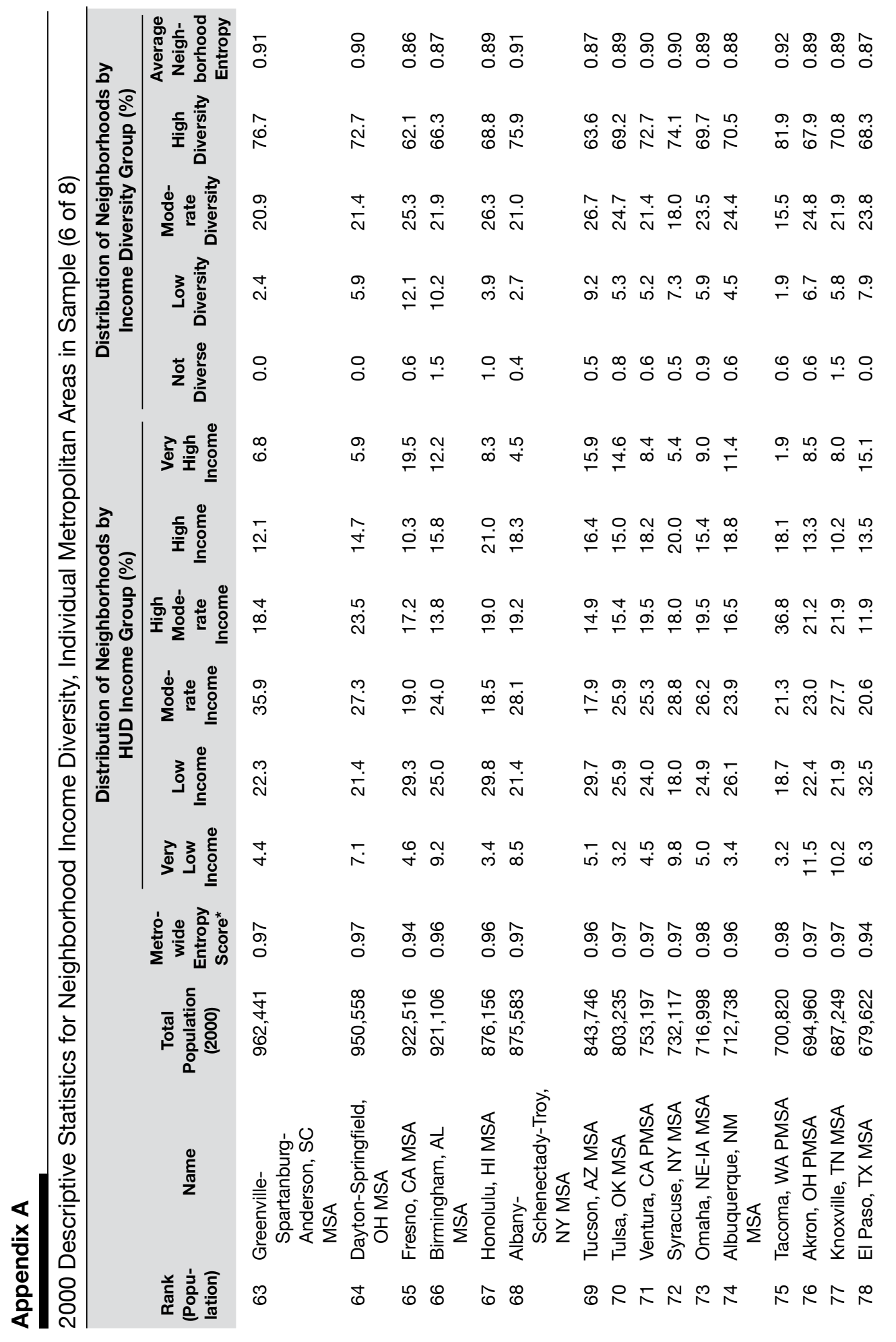




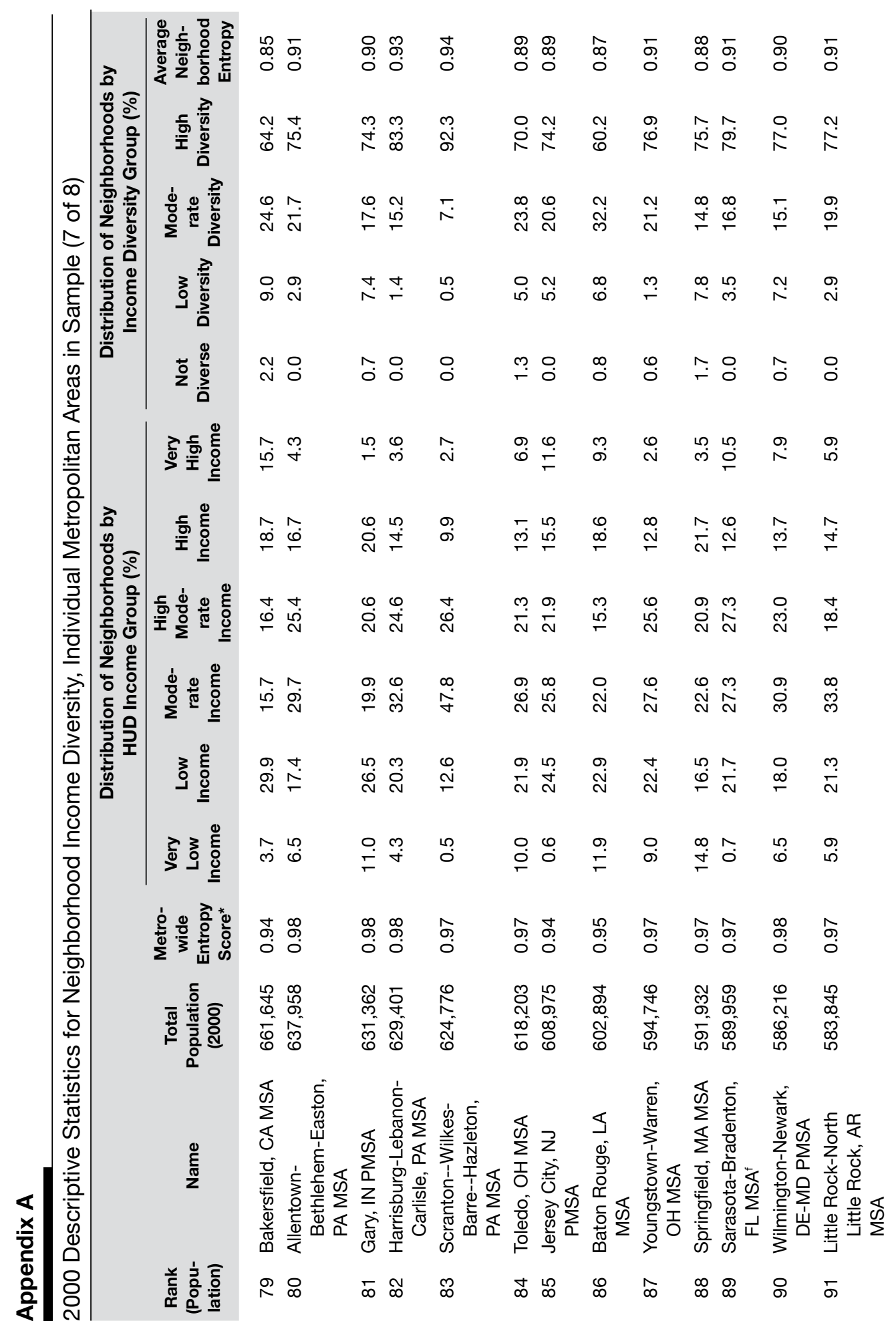




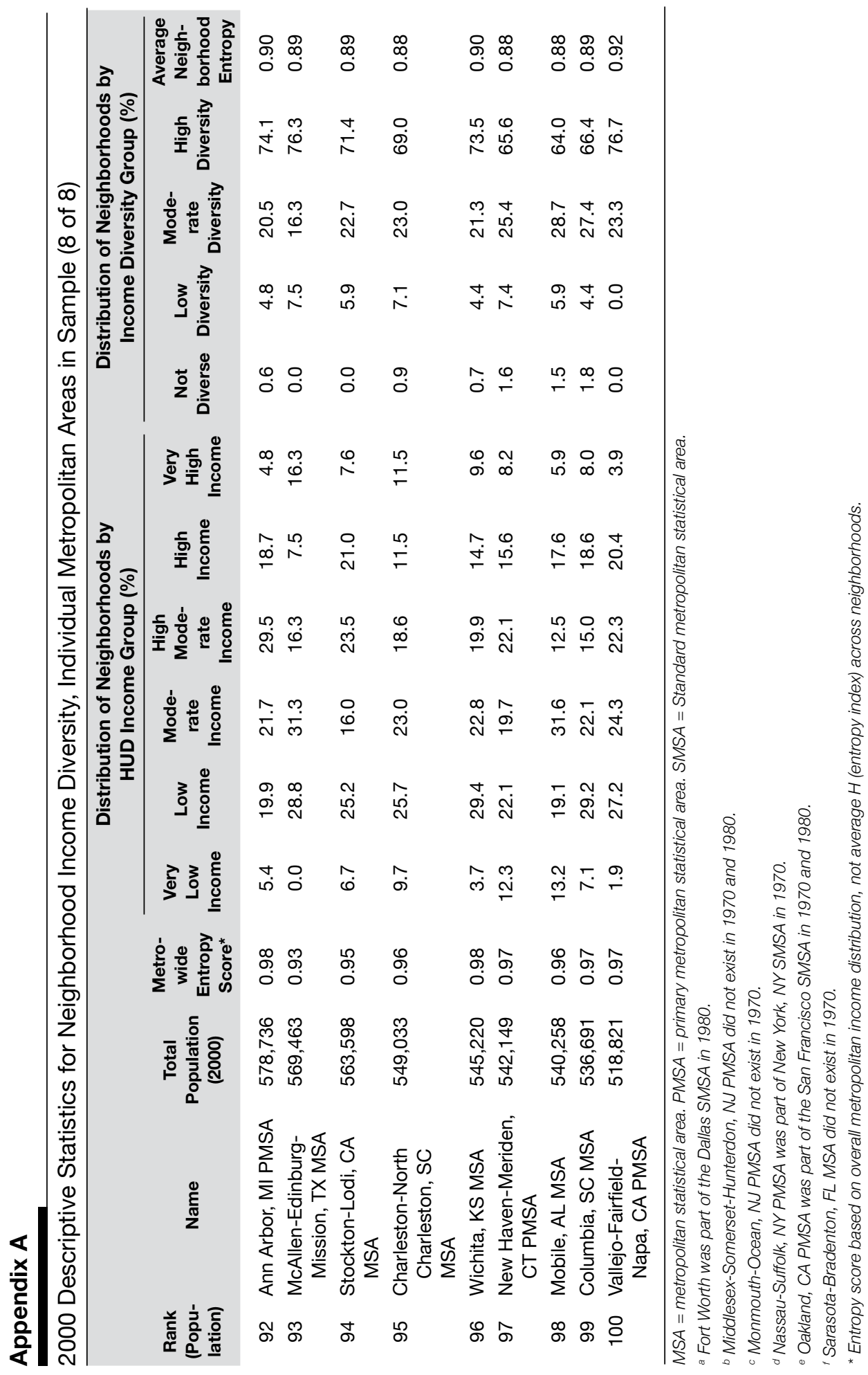




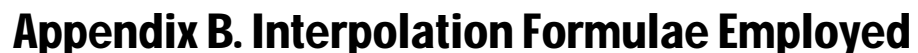

\section{Linear Interpolation}

$\mathrm{P}=\frac{(Y-a)}{(b-a)} \times\left(P_{b}-P_{a}\right)+P_{a}$

\section{Pareto Interpolation}

$$
\Theta=\frac{\ln \left(1-P_{a}\right)-\ln \left(1-P_{b}\right)}{\ln (b)-\ln (a)}
$$

Where:

$\mathrm{Y}=$ Income at percentile of interest

$\mathrm{P}=$ Percentile of interest

$\mathrm{a}=$ The income value at the lower limit of the group containing $\mathrm{P}$

$\mathrm{b}=$ The income value at the upper limit of the group containing $\mathrm{P}$

$\mathrm{P}_{\mathrm{a}}=$ Proportion of the distribution that lies below the lower limit

$\mathrm{P}_{\mathrm{b}}^{\mathrm{a}}=$ Proportion of the distribution that lies below the upper limit

Source: Berube and Tiffany (2004)

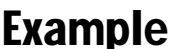

The following example provides an illustration of how Pareto interpolation can be used to estimate a specific frequency based on a group frequency distribution. To determine the frequency of cases below a certain income value $(\mathrm{Y})$, we would use grouped income distribution parameters provided in the decennial census, including the income value at the lower limit of the group containing the income in question (a), the upper limit of the group (b), the proportion of the population that lies below the lower limit $\left(\mathrm{P}_{\mathrm{a}}\right)$, and the proportion of the population that lies below the upper limit $\left(\mathrm{P}_{\mathrm{b}}\right)$. Using the following hypothetical values, Pareto interpolation can be used to determine the proportion of the population $(\mathrm{P})$ that lies below the income value of interest $(\mathrm{Y})$.

$\mathrm{Y}=\$ 54,491$

$\mathrm{a}=\$ 50,000$

$\mathrm{b}=\$ 60,000$

$\mathrm{P}_{\mathrm{a}}=0.5$

$\mathrm{P}_{\mathrm{b}}=0.6$

Using the Pareto interpolation formula, the unknown values of $k, \Theta$, and $\mathrm{P}$ are as follows:

$\mathrm{k}=\$ 27,742$

$\Theta=1.28$

$\mathrm{P}=0.58$

In other words, the proportion of the population that lies below a value of $\$ 54,491$ is estimated to be 0.58

$\Theta=\left(\frac{\ln \left(1-P_{a}\right)-\ln \left(1-P_{b}\right)}{\ln (b)-\ln (a)}\right)$ 
$\Theta=\left(\frac{\ln (1-0.5)-\ln (1-0.6)}{\ln (\$ 60,000)-\ln (\$ 50,000)}\right)$

$\Theta=1.28$

$k=\left(\frac{P_{b}-P_{a}}{\frac{1}{a^{\ominus}}-\frac{1}{b^{\ominus}}}\right)^{\frac{1}{\Theta}}$

$k=\left(\frac{0.6-0.5}{\frac{1}{\$ 50,000^{1.28}}-\frac{1}{\$ 60,000^{1.28}}}\right)^{\frac{1}{1.28}}$

$k=\$ 27,742$

$\mathrm{P}=1-\left(\frac{\$ 27,742}{\$ 54,491}\right)^{1.28}$

$\mathrm{P}=\left(1-\frac{k}{Y}\right)^{\Theta}$

$P=0.58$

\section{Acknowledgments}

The authors thank Mark Shroder and anonymous referees for their valuable suggestions for modifying an earlier version of this article.

\section{Authors}

George C. Galster is the Clarence Hilberry Professor of Urban Affairs in the Department of Geography and Urban Planning, Wayne State University.

Jason C. Booza is a research assistant in the Department of Family Medicine and Public Health Sciences, Wayne State University.

Jackie M. Cutsinger is a research assistant in the Center for Urban Studies, Wayne State University. 


\section{References}

Abramson, Alan. J., Mitchell S. Tobin, and Matthew R. VanderGoot. 1995. "The Changing Geography of Metropolitan Opportunity: The Segregation of the Poor in U.S. Metropolitan Areas, 1970 to 1990," Housing Policy Debate 6 (1): 45-72.

Allison, Paul D. 1978. "Measures of Inequality," American Sociological Review 43 (6): 865-880.

Berube, Alan, and Thatcher Tiffany. 2004. The Shape of the Curve: Household Income Distributions in U.S. Cities, 1979-1999. Washington, DC: Brookings Institution.

Briggs, Xavier deSouza, editor. 2005. The Geography of Opportunity. Washington, DC: Brookings Institution.

Briggs, Xavier deSouza. 1998. "Brown Kids in White Suburbs: Housing Mobility and the Many Faces of Social Capital," Housing Policy Debate 9 (1): 177-221.

Chase-Lansdale, P. Lindsay, Rachel A. Gordon, Jeanne Brooks-Gunn, and Pamela K. Klebanov. 1997. "Neighborhood and Family Influences on the Intellectual and Behavioral Competence of Preschool and Early School-Age Children." In Neighborhood Poverty: Vol. 1. Context and Consequences for Children, edited by Jeanne Brooks-Gunn, Greg J. Duncan, and J. Lawrence Aber. New York: Russell Sage Foundation: 79-118.

Clampet-Lundquist, Susan. 2004. "HOPE VI Relocation: Moving to New Neighborhoods and Building New Ties," Housing Policy Debate 15 (3): 415-447.

Crane, Jonathan. 1991. "The Epidemic Theory of Ghettos and Neighborhood Effects on Dropping Out and Teenage Childbearing," American Journal of Sociology 96 (5): 1226-1259.

Duncan, Greg J., James P. Connell, and Pamela K. Klebanov. 1997. "Conceptual and Methodological Issues in Estimating Causal Effects of Neighborhoods and Family Conditions on Individual Development." In Neighborhood Poverty: Vol. 1. Context and Consequences for Children, edited by Jeanne Brooks-Gunn, Greg J. Duncan, and J. Lawrence Aber. New York: Russell Sage Foundation: 219-250

Ellen, Ingrid Gould. 1998. "Stable Racial Integration in the Contemporary United States: An Empirical Overview," Journal of Urban Affairs 20 (1): 27-42.

Ellen, Ingrid Gould, and Margery Austin Turner. 2003. "Do Neighborhoods Matter and Why?" In Choosing a Better Life? Evaluating the Moving To Opportunity Experiment, edited by John Goering and Judith Feins. Washington, DC: Urban Institute Press: 313-338

Farley, Reynolds. 1977. "Residential Segregation in Urbanized Areas of the United States in 1970: An Analysis of Social Class and Racial Differences," Demography 14 (4): 497-518.

Firebaugh, Glen. 1999. "Empirics of World Income Inequality," American Journal of Sociology 104 (6): 1597-1630. 
Fischer, Claude S., Gretchen Stockmayer, Jon Stiles, and Michael Hout. 2004. "Distinguishing the Geographic Levels and Social Dimensions of U.S. Metropolitan Segregation, 1960-2000," Demography 41 (1): 37-59.

Fischer, Mary J. 2003. "The Relative Importance of Income and Race in Determining Residential Outcomes in U.S. Urban Areas 1970-2000," Urban Affairs Review 38 (5): 669-696.

Fong, Eric, and Kumiko Shibuya. 2000. "The Spatial Separation of the Poor in Canadian Cities," Demography 37 (4): 449-459.

Galster, George, Roger Andersson, Sako Musterd, and Timo Kaupinnen. 2008. "Does Neighborhood Income Mix Affect Adult Incomes? New Evidence from Sweden," Journal of Urban Economics 63: 858-870.

Galster, George, and Jason Booza. 2007. "The Rise of the Bipolar Neighborhood," Journal of the American Planning Association 73 (4): 421-435.

Galster, George, and Sean Killen. 1995. "The Geography of Metropolitan Opportunity: A Reconnaissance and Conceptual Framework," Housing Policy Debate 6 (1): 7-43.

Galster, George, and Ron Mincy. 1993. "Explaining the Changing Fortunes of Metropolitan Neighborhoods, 1980-1990," Housing Policy Debate 4 (3): 303-354.

Galster, George, Roberto Quercia, Alvaro Cortes, and Ron Malega. 2003. "The Fortunes of Poor Neighborhoods," Urban Affairs Review 39 (2): 205-227.

Galster, George, Peter Tatian, Anna Santiago, Kathryn Pettit, and Robin Smith. 2003. Why NOT in My Back Yard? The Neighborhood Impacts of Assisted Housing. New Brunswick, NJ: Rutgers University, Center for Urban Policy Research Press.

Gephardt, Martha A. 1997. "Neighborhoods and Communities as Contexts for Development." In Neighborhood Poverty: Vol. 1. Context and Consequences for Children, edited by Jeanne Brooks-Gunn, Greg J. Duncan, and J. Lawrence Aber. New York: Russell Sage Foundation: 1-43.

Granovetter, Mark. 2005. "The Impact of Social Structures on Economic Outcomes," Journal of Economic Perspectives 19 (1): 33-50.

Hardman, Anna, and Yannis M. Ioannides. 2004a. "Neighbors' Income Distribution: Economic Segregation and Mixing in U.S. Urban Neighborhoods," Journal of Housing Economics 13: 368-382.

2004b. Income Mixing and Housing in U.S. Cities: Evidence from Neighborhood Clusters of the American Housing Survey. Unpublished paper. Tufts University, Department of Economics,

Harsman, Bjorn, and John M. Quigley. 1995. "The Spatial Segregation of Ethnic and Demographic Groups: Comparative Evidence from Stockholm and San Francisco," Journal of Urban Economics 37: $1-16$.

Iceland, John. 2004. "Beyond Black and White: Residential Segregation in Multiethnic America," Social Science Research 33 (2): 248-271. 
Iceland, John., Daniel Weinberg, and Erika Steinmetz. 2002. Racial and Ethnic Segregation in the United States: 1980-2000. U.S. Census Bureau, Census Special Report, CENSR-3. Washington, DC: U.S. Government Printing Office.

Immergluck, Dan., and Geoff Smith. 2002. "Who's Buying Where? The Second of Two Reports on Home Buying and Neighborhood Change in the Chicago Area in the 1990s." Chicago: The Woodstock Institute.

Ioannides, Yannis M. 2004. "Neighborhood Income Distributions," Journal of Urban Economics 56: $435-457$.

Ioannides, Yannis M., and Tracey N. Seslen. 2002. "Neighborhood Wealth Distributions," Economic Letters 76: 357-367.

James, David R., and Karl E. Taeuber, 1985. "Measures of Segregation," Sociological Methodology 15: $1-32$.

Jargowsky, Paul A. 2003. Stunning Progress, Hidden Problems: The Dramatic Decline of Concentrated Poverty in the 1990s. Washington, DC: Brookings Institution.

- 1997. Poverty and Place: Ghettos, Barrios, and the American City. New York: Russell Sage Foundation.

1996a. "Take the Money and Run: Economic Segregation in U.S. Metropolitan Areas," American Sociological Review 61 (6): 984-998.

1996b. "Beyond the Street Corner: The Hidden Diversity of High-Poverty

Neighborhoods," Urban Geography 17 (7): 579-603.

1994. "Ghetto Poverty among Blacks in the 1980s," Journal of Policy Analysis and Management 13: 288-310.

Jones, Arthur. F., and Daniel H. Weinberg. 2000. The Changing Shape of the Nation's Income Distribution. Washington, DC: U.S. Census Bureau: 60-204.

Joseph, Mark L. 2006. "Is Mixed-Income Development an Antidote to Urban Poverty?" Housing Policy Debate 17 (2): 209-234.

Joseph, Mark L., Robert J. Chaskin, and Henry S. Webber. 2006. "The Theoretical Basis for Addressing Poverty Through Mixed-Income Development," Urban Affairs Review 42 (3): 369-409.

Kasarda, John D. 1993. "Inner-City Concentrated Poverty and Neighborhood Distress: 1970 to 1990," Housing Policy Debate 4 (3): 253-302.

Kleit, Rachel. 2005. "HOPE VI New Communities: Neighborhood Relationships in Mixed-Income Housing," Environment and Planning A 37 (8): 1413-1441.

2002. "Job Search Networks and Strategies in Scattered-Site Public Housing," Housing Studies 17 (1): 83-100. 
- 2001a. "The Role of Neighborhood Social Networks in Scattered-Site Public Housing Residents' Search for Jobs," Housing Policy Debate 12 (3): 541-573.

- 2001b. "Neighborhood Relations in Scattered-Site and Clustered Public Housing," Journal of Urban Affairs 23 (3, 4): 409-430.

Kohen, Dafna E., Jeanne Brooks-Gunn, Tama Leventhal, and Clyde Hertzman. 2002.

"Neighborhood Income and Physical and Social Disorder in Canada: Associations with Young Children's Competencies," Child Development 73 (6): 1844-1860.

Krupka, Douglas J. 2006. The Stability of Mixed-Income Neighborhoods in America, 1990-2000. Working paper no. 06-08. Atlanta: Georgia State University, Urban and Regional Analysis Working Group.

Lee, Barrett A., and Peter B. Wood. 1990. "The Fate of Residential Integration in American Cities: Evidence from Racially Mixed Neighborhoods, 1970-1980," Journal of Urban Affairs 12 (4): 425-436.

Leventhal, Tama, and Jeanne Brooks-Gunn. 2000. "The Neighborhoods They Live In," Psychological Bulletin 126 (2): 309-337.

Massey, Douglas S., and Nancy A. Denton. 1988. "The Dimensions of Residential Segregation," Social Forces 67 (2): 281-315.

Massey, Douglas S., and Mitchell Eggers. 1993. "The Spatial Concentration of Affluence and Poverty During the 1970s," Urban Affairs Quarterly 29 (2): 299-315.

- 1990. "The Ecology of Inequality: Minorities and the Concentration of Poverty 1970-1980,” American Journal of Sociology 95 (5): 1153-1188.

Massey, Douglas S., and Mary Fischer. 2003. "The Geography of Inequality in the United States, 1950-2000." In Brookings-Wharton Papers on Urban Affairs.

Mayer, Susan E. 2001. How the Growth of Income Inequality Increased Economic Segregation. JCPR working papers. Chicago: Northwestern University, University of Chicago Joint Center for Poverty Research.

Quercia, Roberto, and George C. Galster. 1997. "Threshold Effects and the Expected Benefits of Attracting Middle-Income Households to the Central City," Housing Policy Debate 8 (2): 409-435.

Popkin, Susan, Laura Harris, and Mary Cunningham. 2002. Families in Transition: A Qualitative Analysis of the MTO Experience. Report prepared for the U.S. Department of Housing and Urban Development. Washington, DC: Urban Institute.

Reardon, Sean F., and Glenn Firebaugh. 2002. "Measures of Multigroup Segregation," Sociological Methodology 32 (1): 33-67.

Reardon, Sean F., and John T. Yun. 2001. "Suburban Racial Change and Suburban School Segregation, 1987-95," Sociology of Education 74 (2): 79-101. 
Rosenbaum, Emily, Laura Harris, and Nancy Denton. 2003. "New Places, New Faces: An Analysis of Neighborhoods and Social Ties Among MTO Movers in Chicago." In Choosing a Better Life? Evaluating the Moving To Opportunity Experiment, edited by John Goering and Judith Feins. Washington, DC: Urban Institute Press: 275-310.

Rosenbaum, James. 1995. "Changing the Geography of Opportunity by Expanding Residential Choice: Lessons from the Gautreaux Program," Housing Policy Debate 6 (1): 231-269.

1991. "Black Pioneers: Do Moves to the Suburbs Increase Economic Opportunity for Mothers and Children?" Housing Policy Debate 2 (4): 1179-1213.

Rosenbaum, James, Lisa Reynolds, and Stefanie DeLuca. 2002. "How Do Places Matter? The Geography of Opportunity, Self-Efficacy, and a Look Inside the Black Box of Residential Mobility," Housing Studies 17 (1): 71-82.

Sampson, Robert, Jeffrey Morenoff, and Thomas Gannon-Rowley. 2002. "Assessing 'Neighborhood Effects': Social Processes and New Directions in Research," Annual Review of Sociology 28: 443-478.

Schill, Michael. 1997. "Chicago's New Mixed-Income Communities Strategy: The Future Face of Public Housing?" In Affordable Housing and Urban Redevelopment in the United States, edited by Willem Van Vliet. Thousand Oaks, CA: Sage: 135-157.

Suttles, Gerald. 1972. The Social Construction of Communities. Chicago: University of Chicago Press. Swanstrom, Todd, Colleen Casey, Robert Flack, and Peter Dreier. 2004. "Pulling Apart: Economic Segregation among Suburbs and Central Cities in Major Metropolitan Areas." Washington, DC: The Brookings Institution.

Talen, Emily. 2006. "Neighborhood-level Social Diversity: Insights from Chicago," Journal of the American Planning Association, 72(4), 431-446.

Tatian, Peter. A. 2002. Census CD Neighborhood Change Database (NCDB) Data Users' Guide: Short Form Release. Washington, DC: The Urban Institute.

Telles, Edward E. 1995. "Structural Sources of Socioeconomic Segregation in Brazilian Metropolitan Areas," American Journal of Sociology 100 (5): 1199-1223.

Thomas, June M., John H. Schweitzer, and Julia A. Darnton. 2004. "Mixed Income Neighborhoods: Issues of Assessment." Paper presented at the annual meeting of the Urban Affairs Association, Washington, DC.

Turner, Margery Austin, and Julie Fenderson. 2006. "Understanding Diverse Neighborhoods in an Era of Demographic Change." Washington, DC: Urban Institute, Metropolitan Housing and Policy Center.

U.S. Bureau of the Census. 1981. Census of Population: 1980. Vol. I, Characteristics of the Population PC80-1, Part I, United States Summary, Section C: SCSAs. Washington, DC: U.S. Government Printing Office. 
1973. Census of Population: 1970. Vol. I, Characteristics of the Population, Part I, United States Summary-Section 2. Washington, DC: U.S. Government Printing Office.

U.S. Department of Housing and Urban Development (HUD). 1996. Rental Housing Assistance at a Crossroads: A Report to Congress on Worst Case Housing Needs. Washington, DC: U.S. Department of Housing and Urban Development, Office of Policy Development and Research. http://www. huduser.org/Publications/PDF/worstcse.pdf (accessed May 11, 2004).

Watson, Tara. 2007. "New Housing, Income Inequality, and Distressed Metropolitan Areas." Washington, DC: Brookings Institution, Metropolitan Policy Program. http://www.brookings. edu/reports/2007/09newhousing_watson.aspx (accessed December 20, 2007).

White, Michael J. 1986. "Segregation and Diversity Measures in Population Distribution," Population Index 52 (2): 198-221.

Wilson, William Julius. 1987. The Truly Disadvantaged. Chicago: University of Chicago Press. 